\title{
Nilotinib Improves Bioenergetic Profiling in Brain Astroglia in the 3xTg Mouse Model of Alzheimer's Disease
}

\author{
Aida Adlimoghaddam ${ }^{1, *}$, Gary G. Odero', Gordon Glazner ${ }^{1,2}$, R. Scott Turner ${ }^{3}$, Benedict C. \\ Albensi ${ }^{1,2, *}$ \\ ${ }^{1}$ Division of Neurodegenerative Disorders, St. Boniface Hospital Research, Winnipeg, MB, Canada. \\ ${ }^{2}$ Department of Pharmacology \& Therapeutics, University of Manitoba, Winnipeg, MB, Canada. \\ ${ }^{3}$ Department of Neurology, Georgetown University, Washington, DC, USA.
}

[Received June 11, 2020; Revised September 2, 2020; Accepted September 10, 2020]

\begin{abstract}
Current treatments targeting amyloid beta in Alzheimer's disease (AD) have minimal efficacy, which results in a huge unmet medical need worldwide. Accumulating data suggest that brain mitochondrial dysfunction play a critical role in AD pathogenesis. Targeting cellular mechanisms associated with mitochondrial dysfunction in AD create a novel approach for drug development. This study investigated the effects of nilotinib,

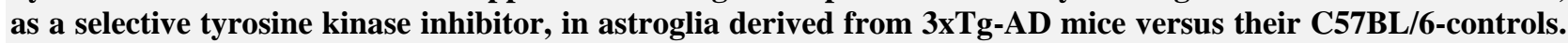
Parameters included oxygen consumption rates (OCR), ATP, cytochrome c oxidase (COX), citrate synthase (CS) activity, alterations in oxidative phosphorylation (OXPHOS), nuclear factor kappa B (NF- $\mathrm{kB}$ ), key regulators of mitochondrial dynamics (mitofusin (Mfn1), dynamin-related protein 1 (Drp1)), and mitochondrial biogenesis (peroxisome proliferator-activated receptor gamma coactivator1-alpha (PGC-1 $\alpha$ ), calcium/calmodulindependent protein kinase II (CaMKII), and nuclear factor (erythroid-derived 2)-like 2 (Nrf2)). Nilotinib increased OCR, ATP, COX, Mfn1, and OXPHOS levels in 3xTg astroglia. No significant differences were detected in levels of Drp1 protein and CS activity. Nilotinib enhanced mitochondrial numbers, potentially through a CaMKII-PGC1 $\alpha$-Nrf2 pathway in 3xTg astroglia. Additionally, nilotinib-induced OCR increases were reduced in the presence of the NF- $\kappa B$ inhibitor, Bay11-7082. The data suggest that $\mathrm{NF}-\kappa \mathrm{B}$ signaling is intimately involved in nilotinib-induced changes in bioenergetics in 3xTg brain astroglia. Nilotinib increased translocation of the NF- $\kappa \mathrm{B}$ p50 subunit into the nucleus of 3xTg astroglia that correlates with an increased expression and activation of NF-kB. The current findings support a role for nilotinib in improving mitochondrial function and suggest that astroglia may be a key therapeutic target in treating AD.
\end{abstract}

Key words: mitochondrial function, bioenergetics, biogenesis, Alzheimer's disease, astroglia, nuclear factor kappa B (NF- $\kappa \mathrm{B})$, cytochrome c oxidase, citrate synthase, and oxidative phosphorylation

Alzheimer's disease (AD) is a multifactorial classic hallmark of AD [2,3], have failed for the most part
neurodegenerative disorder, characterized by progressive to show efficacy for stopping or slowing cognitive
cognitive impairments [1]. Approaches focusing on decline. However, accumulating evidence demonstrates
therapeutics that interfere with amyloid $\beta$ plaques $(A \beta)$, a mitochondrial dysfunction early in the pathology of

*Correspondence should be addressed to: Dr. Aida Adlimoghaddam and Dr. Benedict C Albensi, Division of Neurodegenerative Disorders, St. Boniface Hospital Research, Winnipeg, MB, Canada. Emails: aadlimoghaddam@ @brc.ca and balbensi@ sbrc.ca.

Copyright: () 2020 Adlimoghaddam A. et al. This is an open-access article distributed under the terms of the Creative Commons Attribution License, which permits unrestricted use, distribution, and reproduction in any medium, provided the original author and source are credited. 
human diseases, cardiovascular, neurodegenerative, and cancers, which may serve as an important and primary therapeutic target [4-9]. Low doses of the anti-cancer drug nilotinib suggest cognitive benefits for patients with Parkinson's disease (PD) and related dementias $[10,11]$. Nilotinib (Tasigna ${ }^{\circledR}$, AMN107) is a c-Abl tyrosine kinase inhibitor approved by the Food and Drug Administration (FDA) for patients with chronic myeloid leukemia (CML) $[12,13]$. Compared to the other c-Abl inhibitors, low dose nilotinib is more advantageous for penetrating the blood brain barrier (BBB) and degrades $\alpha$-synuclein through a process of autophagy in PD models [14-17]. Safety and efficacy of nilotinib in AD patients has been tested. It has recently been reported that biomarkers of $\mathrm{AD}$ were changed as a function of nilotinib treatment [18]. Moreover, nilotinib enhances dopaminergic neurons and improves motor function in PD and Lewy body dementia (LBD) $[10,14]$. The level of c-Abl is elevated in postmortem brains of patients with AD and PD [19-21]. Proteomic analyses show that c-Abl phosphorylates tau tangles in AD brains [19]. In PD models, c-Abl increased oxidative stress, presumably due to the accumulation of dysfunctional mitochondria that generate and release reactive oxygen species (ROS) [21, 22]. Overexpression of glial c-Abl leads to inflammation and neurodegeneration [23, 24]. Under oxidative stress conditions, $\mathrm{c}-\mathrm{Abl}$ is activated in astroglia and blocking cAbl prevented the oxidative death of astroglia [25]. More research identified that overexpression of glial c-Abl contributes to both oxidative stress as well as inflammation in a mouse pain model [24]. Moreover, cAbl inhibitors reduced both inflammatory activation of glia and chronic pain [26].

Astroglia, as important central nervous system (CNS) cells, play key roles in the pathogenesis of neurodegenerative disorders such as $\mathrm{AD}$; excessive oxidative stress, inflammation as well as mitochondrial impairment is observed in $\mathrm{AD}$. Accumulating evidence highlights the critical role of astroglia in inflammatory, oxidative stress, modulation of synaptic activity, and bioenergetic changes present in $\mathrm{AD}$ [27-31]. According to all of these functional properties, astroglia have become exciting targets for our study. The effect of nilotinib on metabolic activity and inflammation in astroglia, however, has not been examined.

The notion of testing nilotinib for $\mathrm{AD}$ may seem counterintuitive since AD involves cell loss and cancer involves unregulated cell proliferation, but the earliest deficits in the pathological progression of $\mathrm{AD}$ and cancer are associated with mitochondrial dysfunction; that is, before the robust appearance of neurotoxic proteins in $\mathrm{AD}$ and oncogene expression in cancer [4-8, 32-39].
Therefore, targeting mitochondrial bioenergetics may be a promising new strategy for treating $\mathrm{AD}[5,40$ 44]. Interestingly, mitochondrial function is considered as a target for cancer therapy, but has not been exploited for AD. Reprograming metabolic activity of cancer cells led to non-apoptotic function [45]. This finding indicates that apoptotic pathway is linked to mitochondria and metabolic pathways. Therefore, the linkage between cancer and $\mathrm{AD}$ provides a rational for repurposing existing anticancer drugs for AD.

Previously, our laboratory documented reductions in brain metabolic activity and in the expression of mitochondrial protein subunits (Complexes I-V) in $3 x \mathrm{Tg}$ brain samples estimated to compromise the site of oxidative phosphorylation (OXPHOS) and mitochondrial efficiency through the action of ATP synthesis [8]. Beside down-regulation of OXPHOS capacity in AD, reduced activity of other mitochondrial metabolic enzymes such as citrate synthase (CS) is associated with $\mathrm{AD}$ [46]. Both mitochondrial dynamics (fission and fusion) and number are significantly altered in AD models that ultimately results in mitochondrial dysfunction [47-50]. The effects of nilotinib on mitochondrial function, however, have not been examined. The regulation of mitochondrial function is also linked to nuclear factor kappa B (NF- $\kappa \mathrm{B})$ signaling, a highly-conserved pathway for immune function, mitochondrial function and previously studied in $\mathrm{AD}$ and cancer [43, 51-53]. Some studies reported that NF- $\kappa B$ signaling regulates $A \beta$-induced mitochondrial function and cytochrome c oxidase (COX) activity [54, 55]. Other studies confirm that the enzymatic activity of COX may be modulated by the NF- $\mathrm{BB}$ signaling pathway $[54,56]$. $\mathrm{NF}-\kappa \mathrm{B}$ plays a crucial role in the metabolic activity of $\mathrm{AD}$ and cancer [53,57]. Several studies have also shown that $\mathrm{NF}-\kappa \mathrm{B}$ activity restricts activation of inflammasomes through the removal of damaged mitochondria [53, 5860]. Whether the mitochondrial-related NF- $\mathrm{kB}$ signaling pathway is affected by nilotinib is not known.

Mitochondrial function is partially regulated by calcium/calmodulin-dependent protein kinase (CaMK), a downstream target of the NF- $\kappa \mathrm{B}$, signaling pathway [61]. CaMK has been shown to be a key protein in neurodegeneration, metabolic regulations, and biogenesis [62]. Peroxisome proliferator-activated receptor gamma coactivator 1 (PGC-1 $\alpha$ ), a downstream target of CaMK, has been implicated in mitochondrial biogenesis [63]. Further, PGC- $1 \alpha$ activates transcription factor nuclear factors (Nrf) and mitochondrial transcription factor $\mathrm{A}$ (TFAM), known to regulate mitochondrial biogenesis [64, 65]. The effect of nilotinib on mitochondrial biogenesis in astroglia, however, has not been investigated. 
A

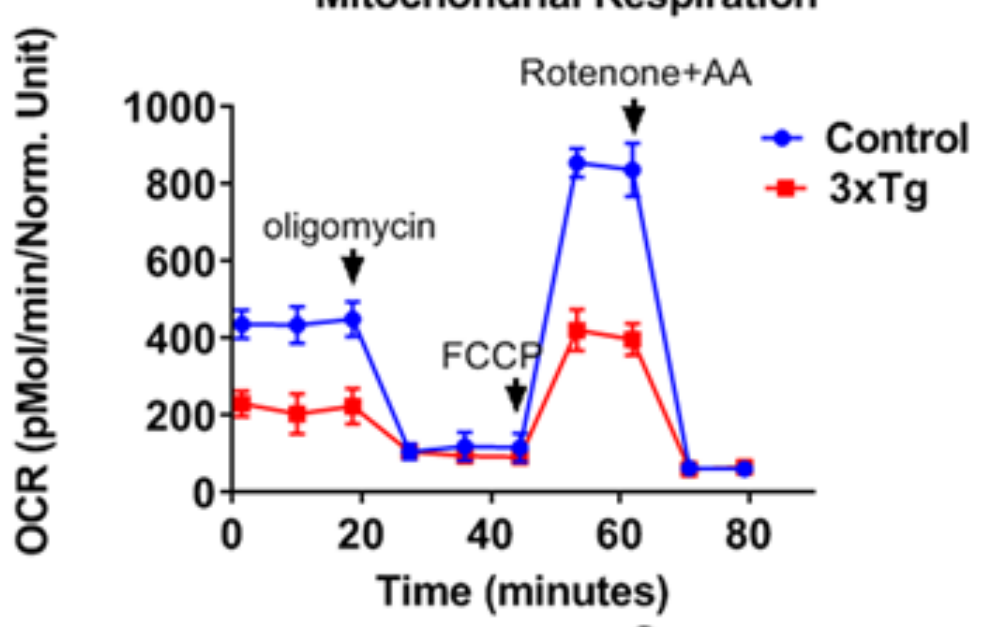

B
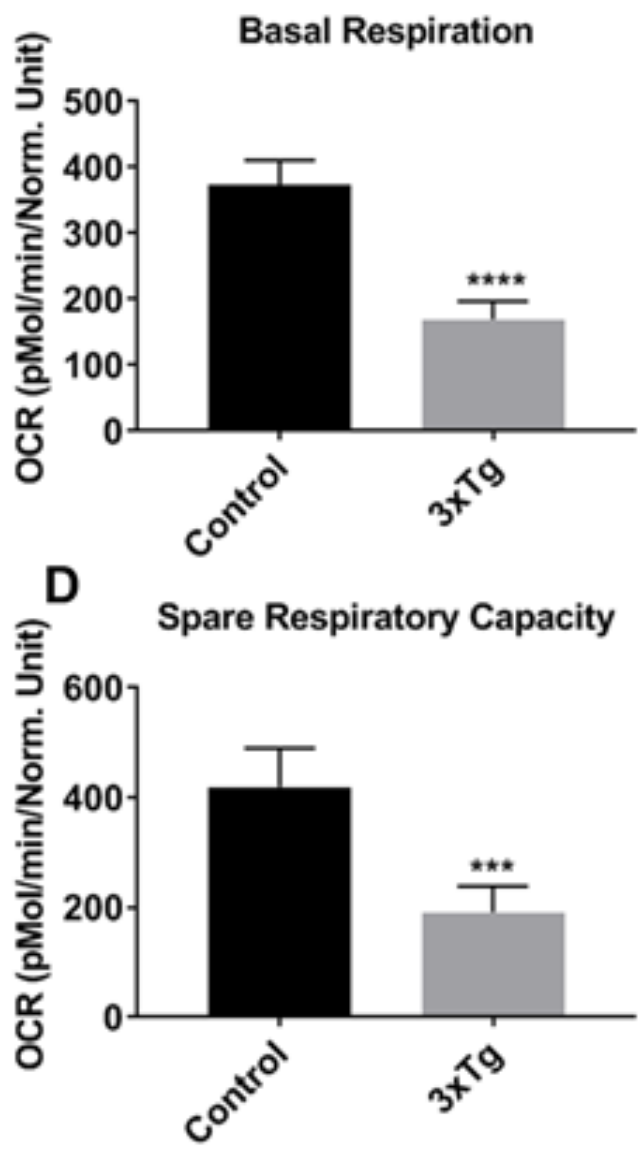

C
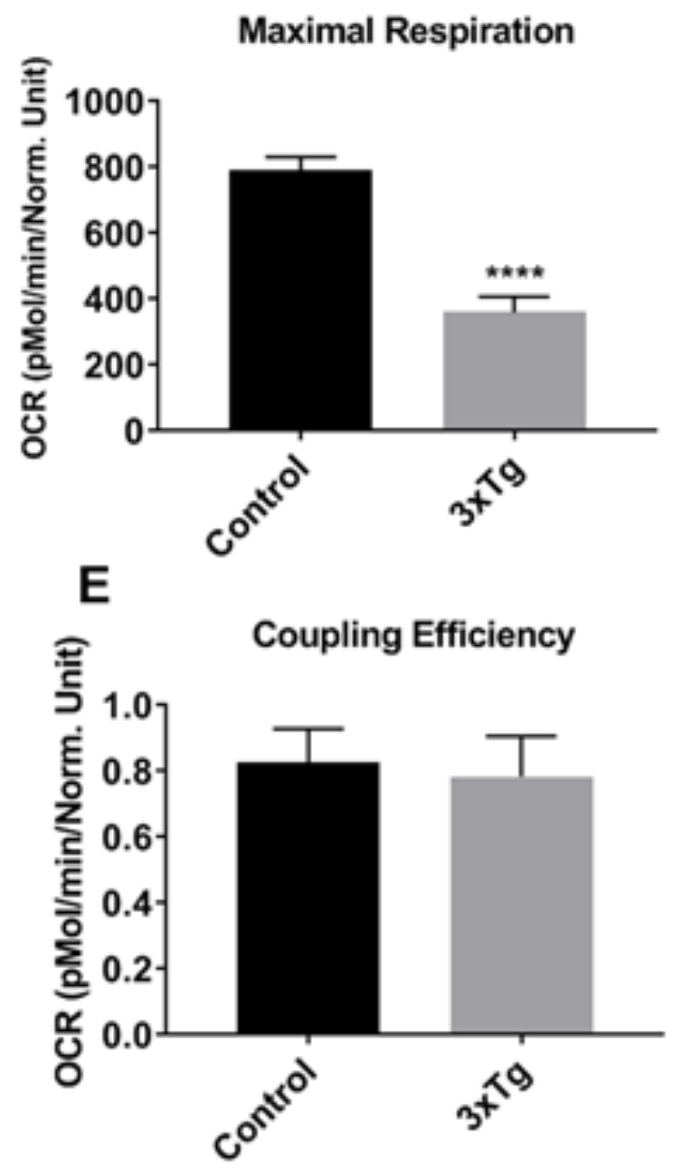

Figure 1. Mitochondrial respiration rates are reduced in 3xTg-AD astroglia. (A) Kinetics graph indicating real-time OCR at baseline and after addition of oligomycin, FCCP, and rotenone/antimycin. The OCR was measured in 3xTg and C57BL/6-WT astroglia utilizing the XF24 analyzer. (B) Basal respiration, (C) maximal respiration, (D) spare respiratory capacity, and (E) Coupling efficiency were calculated compared between $3 \times \mathrm{Tg}$ and control cells. Data are mean \pm SD of $n=6$ per group $(* * *=p<0.001$ or $* * * *=p<0.0001)$ analyzed by unpaired Student's t-test. 
The aim of this study was to test the hypothesis that nilotinib improves astroglia mitochondrial function. We performed bioenergetic profiling in AD vs. wild type (WT)/ control astroglia while in the presence and absence of nilotinib. Specifically, we measured 1) oxygen consumption rates (OCR) and ATP levels; 2) enzymatic activity of COX and CS; 3) levels of OXPHOS; 4) numbers of mitochondria; 5) levels of proteins involved in mitochondrial dynamics (e.g., Mfn1, Drp1); 6) levels of proteins involved in mitochondrial biogenesis (e.g., CaMKII, PGC-1 $\alpha$, Nrf2, and TFAM); 7) translocation, activation, and expression levels of $\mathrm{NF}-\kappa \mathrm{B}$ subunit

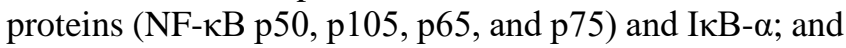
8 ) effects of NF- $\mathrm{B}$ inhibition on cellular respiration and ATP levels.
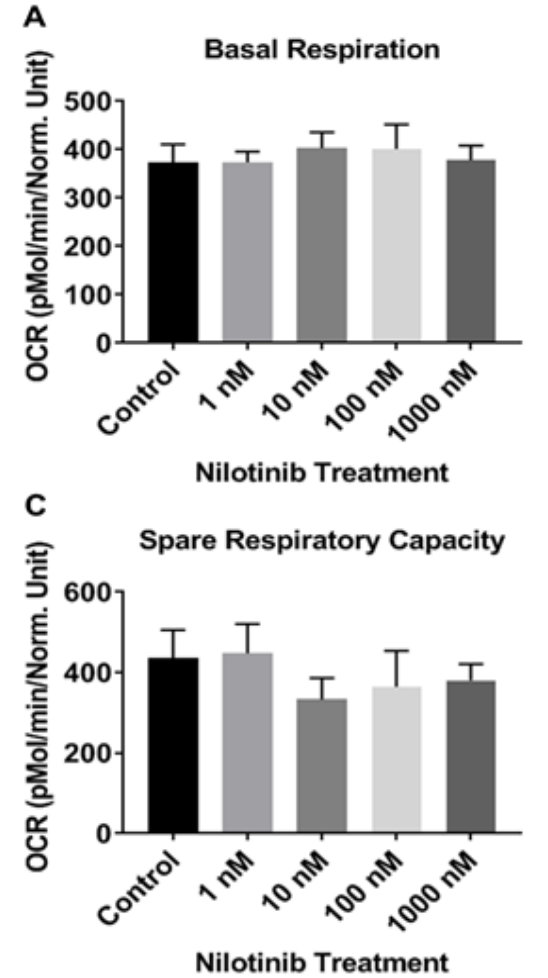

$\mathbf{F}$

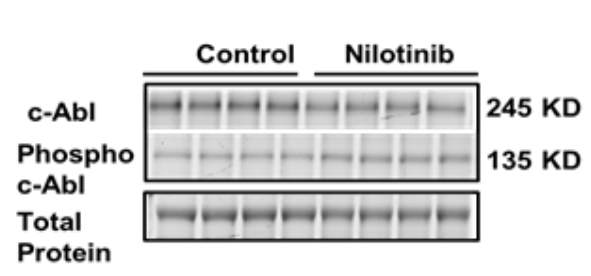

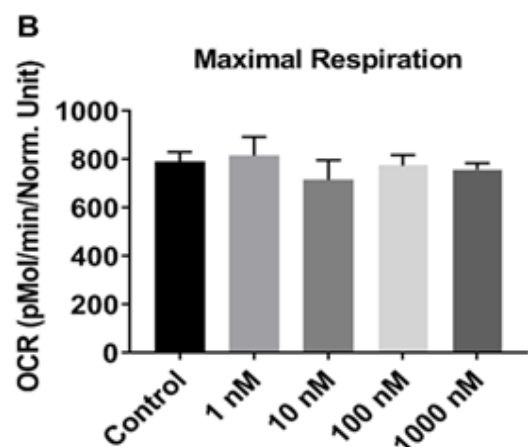

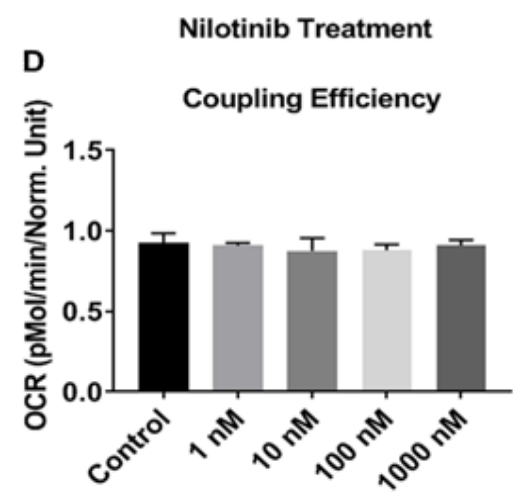

Nilotinib Treatment

G C-Abl

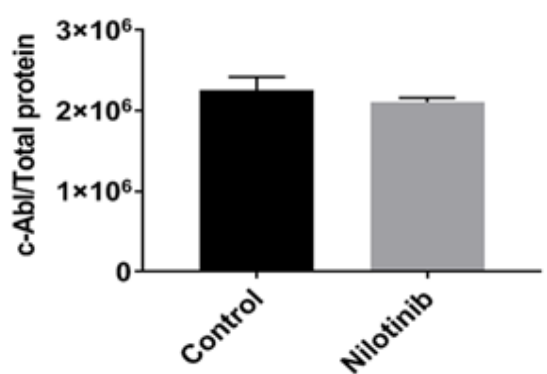

Figure 2. Nilotinib did not alter mitochondrial respiration rate or expression of total or phospho c-Abl in C57BL/6-WT astroglia. The OCR was measured in C57BL/6 astroglia utilizing the XF24 analyzer after 24 hours treatment with nilotinib (1, 10, 100, and 1000 nM). (A) Basal respiration, (B) maximal respiration, (C) spare respiratory capacity, (D) Coupling efficiency, and (E) total ATP level were calculated and compared between control and treated cells. Western blot experiments demonstrating relative levels of c-Abl and p-c-Abl in C57BL/6-WT astroglia (F) in the presence and absence of $24 \mathrm{hrs} .100 \mathrm{nM}$ nilotinib treatment. Relative quantification for protein levels of c-Abl and p-c-Abl normalized to total protein and total c-Abl, respectively $(\mathbf{G}, \mathbf{H})$. Data are mean \pm SD of $n=6$ per group $(*=p<0.05)$ analyzed by unpaired Student's t-test. 


\section{MATERIALS AND METHODS}

\section{Animals}

We utilized both female and male pups (5-7 days) from $3 \times \mathrm{Tg}$ mice. This transgenic model of AD expresses $\mathrm{hAPP}_{\mathrm{Swe}}, \mathrm{hPS} 1_{\mathrm{M} 146 \mathrm{~V}}$, and hTau $301 \mathrm{~L}$ mutations, and exhibit synaptic dysfunction. As a control, female and male pups (5-7 days) derived from wild-type C57BL/6 mice were used. Mice were given ad libitum access to food and water and housed under the standard light/dark cycle ( $12 \mathrm{~h}$ light, $12 \mathrm{~h}$ dark at room temperature $\left.\left(22^{\circ} \mathrm{C}\right)\right)$. All animal procedures followed guidelines of the University of Manitoba Animal Care Committee, the Canadian Council of Animal Care rules, and the Institutional Animal Care and Use Committee (IACUC) standards.
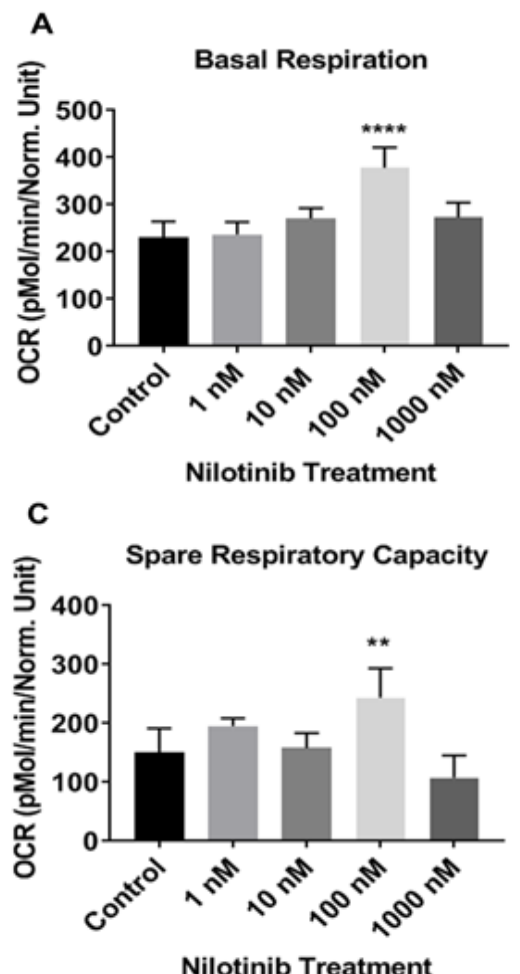

$\mathbf{F}$

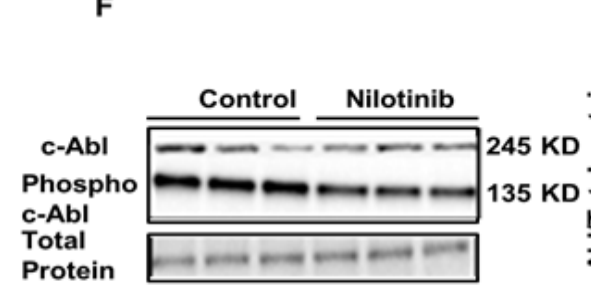

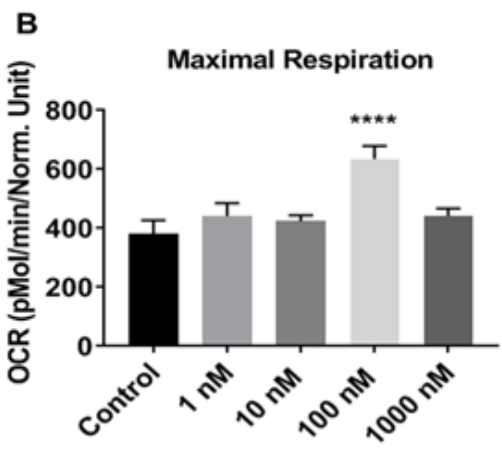

Nilotinib Treatment

D

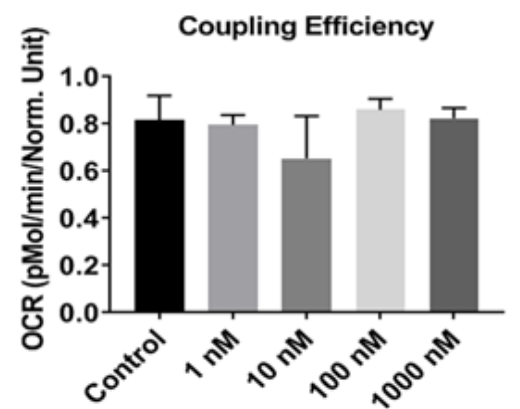

Nilotinib Treatment

G

c-Abl

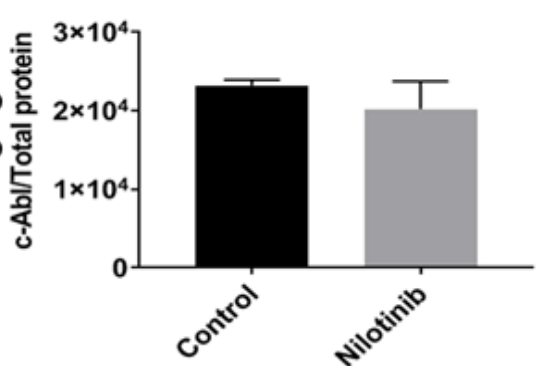

E

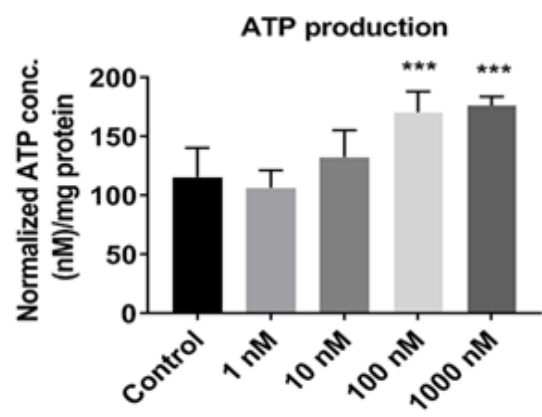

Nilotinib Treatment

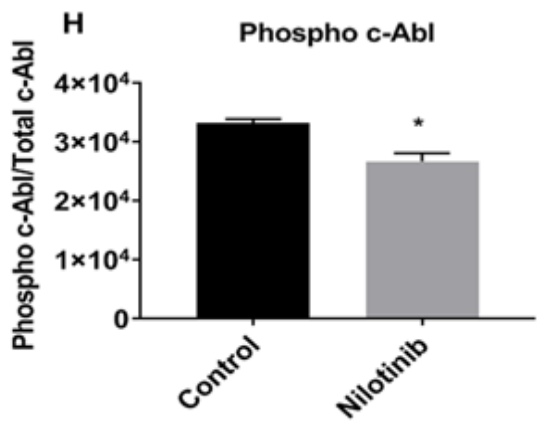

Figure 3. Nilotinib improved mitochondrial respiration rates in 3xTg-AD astroglia. Nilotinib inhibited the expression level of phospho c-Abl in 3xTg astroglia. The OCR was measured in 3xTg-AD astroglia utilizing the XF24 analyzer after 24 hours treatment with nilotinib (1, 10, 100, and $1000 \mathrm{nM})$. (A) Basal respiration, (B) maximal respiration, (C) spare respiratory capacity, (D) coupling efficiency, and (E) total ATP level were calculated and compared between control and treated cells. Western blot experiments demonstrating relative levels of c-Abl and p-c-Abl in 3xTg-AD astroglia (F) in the presence and absence of $24 \mathrm{hrs} .100 \mathrm{nM}$ nilotinib treatment. Relative quantification for protein levels of c-Abl and p-c-Abl normalized to total protein and total c-Abl, respectively $(\mathbf{G}$, H). Data are mean \pm SD of $\mathrm{n}=6$ per group $(*=\mathrm{p}<0.05$ or $* *=\mathrm{p}<0.01$ or $* * *=\mathrm{p}<0.001$ or $* * * *=\mathrm{p}<0.0001)$ analyzed by unpaired Student's t-test. 


\section{Primary cultures of astroglia}

Primary cortical astroglia derived from both $\mathrm{AD}(3 \mathrm{xTg})$ and control (C57BL/6) pups (5-7 days) were prepared as previously described [66]. Briefly, cortical tissue was dissected and placed into a chilled dissection medium [67] composed of $\mathrm{Ca}^{2+}$ and $\mathrm{Mg}^{2+}$ - free Hanks' balanced salt solution (HBSS), $\mathrm{pH} 7.4$, containing the following: 137 $\mathrm{mM} \mathrm{NaCl}, 5.36 \mathrm{mM} \mathrm{KCl}, 0.27 \mathrm{mM} \mathrm{Na} 2 \mathrm{HPO}_{4}, 1.1 \mathrm{mM}$ $\mathrm{KH}_{2} \mathrm{PO}_{4}$, and $6.1 \mathrm{mM}$ glucose. Isolated cortical tissue was sliced using a razor. Following slicing, tissues were gently separated from each other in fresh cold dissecting media and mechanically dissociated by sequential passage through a Pasteur pipette. After dissociation, we centrifuged the cells at 1,000 rpm for $5 \mathrm{~min}$, and the pellet was re-suspended in Dulbecco's modified Eagle's medium (DMEM)/F12 culture medium (Gibco, Grand Island, NY, USA) supplemented with $10 \%$ fetal bovine serum (FBS), $0.5 \mathrm{mg} \mathrm{mL}^{-1}$ streptomycin, $0.5 \mathrm{U} \mathrm{mL}^{-1}$ penicillin (Invitrogen, Carlsbad, CA, USA), $8.39 \mathrm{mM}$ HEPES, and $23.8 \mathrm{mM} \mathrm{NaHCO}_{3}$. Cells derived from $3 \times \mathrm{Tg}-$ $\mathrm{AD}$ and $\mathrm{C} 57 \mathrm{Bl} / 6$ pups were plated on $25-\mathrm{cm}^{2}$ flasks at a density of $6 \times 10^{5}$ cells cm $\mathrm{cm}^{-2}$ and grown at $37^{\circ} \mathrm{C}$ using an incubator with humidified $5 \% \mathrm{CO}_{2}$ and $95 \%$ air. After 12 days, the cell culture reached confluence. Cultures were then shaken gently, and any microglia/floating cells were removed, $[68,69]$ resulting in more than $90 \%$ pure culture of astroglial, as described previously (Supplementary Fig. $1)$.

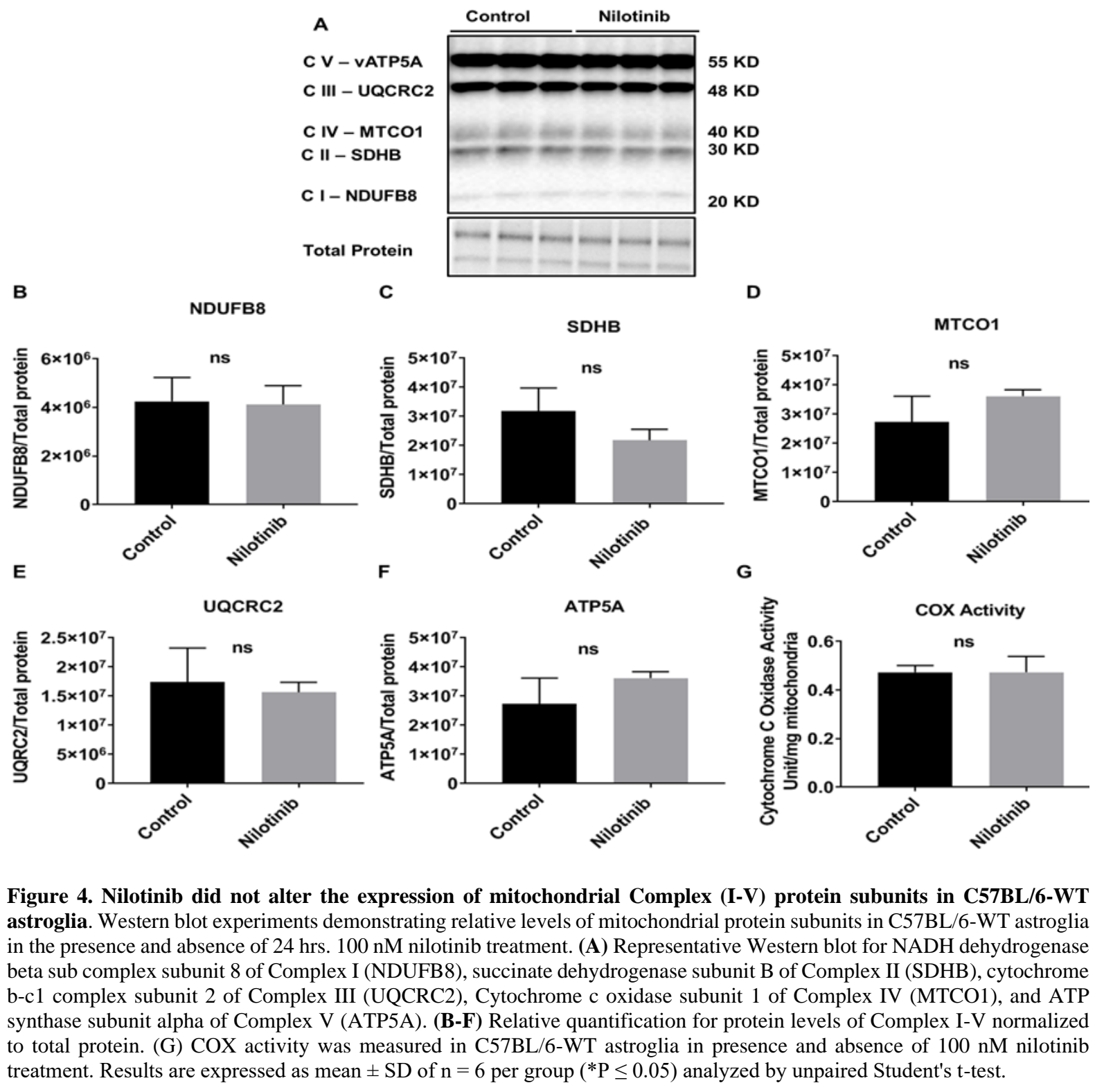




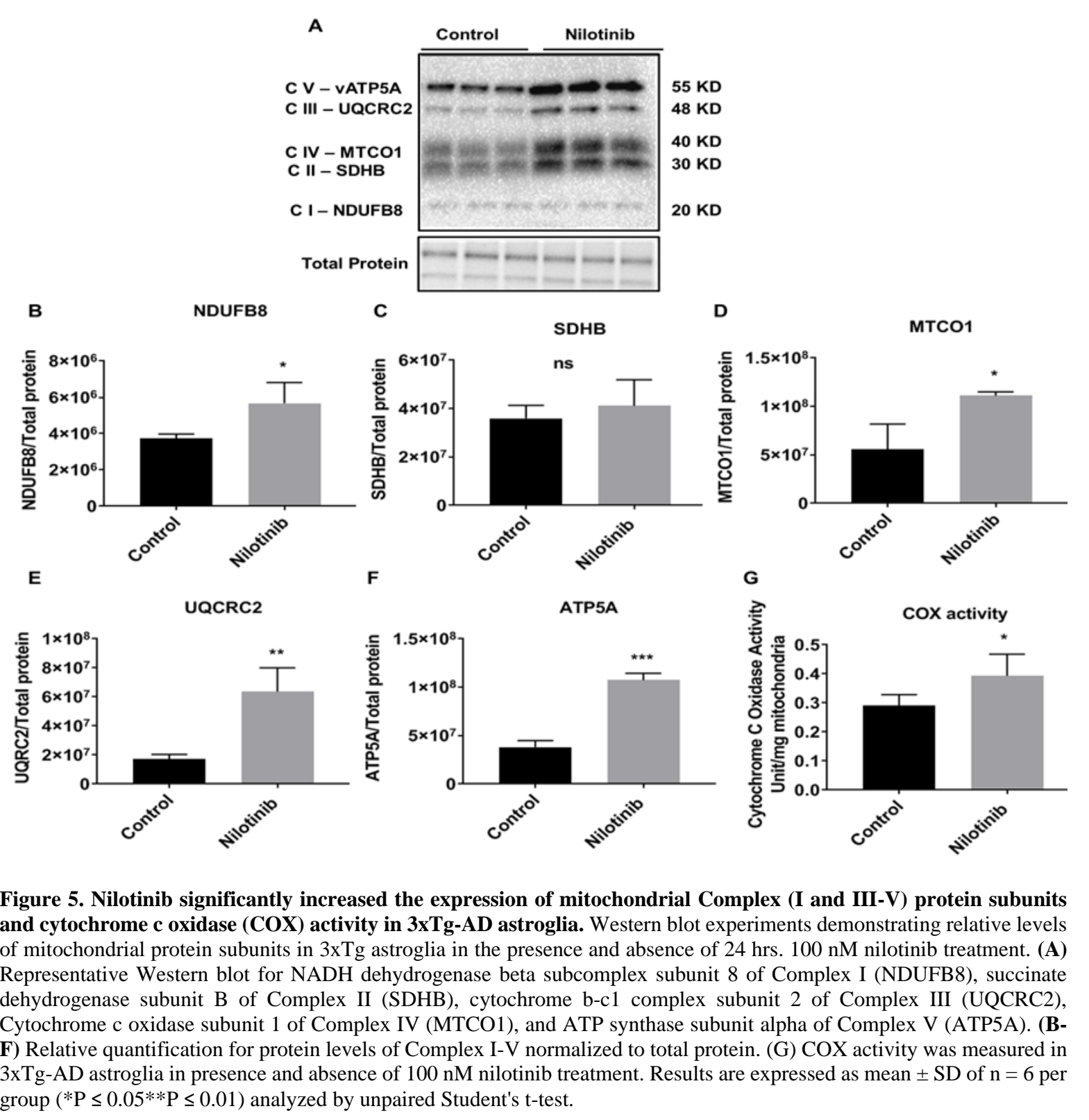

\section{Measurement of mitochondrial respiration rates}

Astroglia derived from 3xTg (AD) and C57BL/6 (control) mice were cultured separately on Seahorse XF24 plates (Seahorse Biosciences, Billerica, MA). To investigate whether nilotinib increased mitochondrial respiration in $3 \times \mathrm{Tg}$ astroglia through the NF- $\mathrm{KB}$ signaling pathway, astroglia were treated with either Bay11-7082, a wellknown NF- $\mathrm{KB}$ inhibitor that has pharmacological activities including neuroprotective, anticancer, and antiinflammatory roles [70], or co-treated with nilotinib and Bay11-7082 for 24 hours. Following treatment, cells were subjected to un-buffered DMEM supplemented with 1 $\mathrm{mM}$ sodium pyruvate, $1 \mathrm{mM}$ glucose, at $\mathrm{pH} 7.4$ and incubated in a non- $\mathrm{CO}_{2}$ incubator for one hour at $37{ }^{\circ} \mathrm{C}$.
First, the basal oxygen consumption rate was measured before injection of selected mitochondrial inhibitors. Second, oligomycin $(1 \mu \mathrm{M})$, an irreversible ATP synthase inhibitor, was added to drive a proton gradient. Third, carbonyl cyanide-p-trifluoromethoxyphenyl-hydrazone, a.k.a FCCP $(1 \mu \mathrm{M})$, an electron transport chain (ETC) uncoupler, was added to lower the proton gradient and allow for maximum respiration of cells. Fourth, rotenone $(1 \mu \mathrm{M})$, a Complex I inhibitor, and antimycin A $(1 \mu \mathrm{M})$, a Complex III inhibitor, were added to cease respiration, thus blocking mitochondrial electron transfer at cytochrome c oxidase. Following the addition of rotenone and antimycin, basal respiratory data were calculated and corrected with subtraction of non-mitochondrial respiration rates. Maximal respiration rate was calculated 
by dividing FCCP-stimulated OCR by OCR oligomycinstimulated OCR. Spare respiratory capacity (ability of the cell to respond to improved energy demand) was approximated by measuring the differences between basal and maximal respiration rates. Coupling efficiency is the proportion of OCR that is utilized to make ATP and was estimated as the fraction of basal mitochondrial OCR used for ATP synthesis (ATP-linked OCR/basal OCR).

For analysis, OCR readings were measured and recorded by Seahorse XF-24 software (Seahorse Biosciences, Billerica, MA). Finally, the OCR level was normalized based on protein concentrations colorometric detergent compatible (DC) protein assay kit (BioRad, Hercules, California, USA)) for each well. The OCR measures from each well were normalized to total protein levels.

\section{Measurement of cellular ATP}

ATP production was determined with a luminescent ATP detection assay kit (ab113849: Abcam, Cambridge, UK) as per manufacturer's instructions. Briefly, cells were washed with phosphate buffered saline (PBS). Then, ATP standard dilutions were made. Further, cells and ATP standard dilutions were incubated with detergent at room temperature (RT) for five minutes on an orbital shaker. After 10 minutes incubation in the dark, ATP levels were measured on a Micoplate Reader (Dynex Technologies, Denkendorf, Germany) by tracking the change of absorbance at $535 / 587 \mathrm{~nm}$.

\section{Measurement of cytochrome c oxidase and citrate synthase enzymatic activity}

The activity of cytochrome c oxidase (COX) and citrate synthase (CS) was assessed spectrophotometrically (Ultrospec 2100 pro; GE Healthcare) using ScienCell assay kits (8278 and 8318, ScienCell Research Laboratory, California, USA) on isolated mitochondria derived from control and 3xTg astroglia. The activity of COX and CS was determined spectrophotometrically by measuring absorbance at $550 \mathrm{~nm}, 412 \mathrm{~nm}$, respectively.

All relative quantification for enzyme assays were analyzed based on densitometry values normalized to total protein level. Protein concentrations were measured utilizing a colorometric DC protein assay kit (BioRad, Hercules, California, USA).

\section{Nuclear protein extraction and electrophoretic mobility shift assay (EMSA)}

Nuclear protein was isolated from astroglia cultures using the NE-PER ${ }^{\mathrm{TM}}$ nuclear and cytoplasmic extraction kit (ThermoFisher Scientific, San Jose, CA, USA) as per the manufacturer's instructions. EMSA, used to study protein: DNA interactions, was performed using the LightShift ${ }^{\mathrm{TM}}$ Chemiluminescent EMSA Kit (ThermoFisher Scientific, San Jose, CA, USA). For the EMSA, $25 \mu \mathrm{L}$ reaction mixtures containing binding buffer (10x binding buffer, $0.05 \mu \mathrm{g} / \mu \mathrm{L}$ Poly $(\mathrm{d}\ulcorner\cdot \mathrm{dC}), 2.5 \%$ glycerol, $0.05 \% \mathrm{NP} 40,5 \mathrm{mM} \mathrm{MgCl} 2,50 \mathrm{mM} \mathrm{KCl}, 1 \mathrm{mM}$ EDTA, $0.5 \mathrm{mg} / \mathrm{mL}$ BSA), $15 \mu \mathrm{g}$ nuclear protein (astroglia) and $40 \mathrm{fM}$ biotinylated probe and $20 \mathrm{fM}$ biotinylated probe, respectively, corresponding to a NF- $\kappa B$-binding site (5'-AGTTGAGGGGACTTTCCCAGGC-3') were incubated at room temperature for 30 minutes. For the competition reaction, $100 \mathrm{pM}$ unbiotinylated probe was added to the nuclear protein/binding buffer reaction for 20 minutes at room temperature after which a $40 \mathrm{fM}$ biotinylated probe was added for 30 minutes at room temperature. A total of $20 \mu \mathrm{L}$ of reaction mixture was loaded on native $6 \%$ polyacrylamide gels prepared in $0.5 \times$ TBE and electrophoresed at $100 \mathrm{~V}$ for 90 minutes at room temperature. Gels were then transferred onto a nylon membrane for 90 minutes at $4^{\circ} \mathrm{C}$ at $380 \mathrm{~mA}$ then UV cross-linked for one minute at $120 \mathrm{~mJ} / \mathrm{cm}^{2}$. The processing of the membrane was performed using the Chemiluminescent Nucleic Acid Detection Module Kit (ThermoFisher Scientific, San Jose, CA, USA) as per the manufacturer's instructions. The nylon membrane was imaged with the Chemidoc ${ }^{\mathrm{TM}}$ MP (Bio-Rad, Hercules, CA, USA).

\section{Protein extraction and Western blot analysis}

Proteins were stored at $-80{ }^{\circ} \mathrm{C}$ prior to Western blotting as previously described [8]. Briefly, astroglia were harvested from the cortex of C57BL/6-control and 3xTg-AD mice and then homogenized in ice-cold radioimmunoprecipitation (RIPA) buffer containing: $150 \mathrm{mM}$ sodium chloride, $50 \mathrm{mM}$ Tris, $\mathrm{pH} 8.0,0.5 \%$ sodium deoxycholate, $0.1 \%$ sodium dodecyl sulfate (SDS), $1 \%$ Triton X-100, $1 \%$ phosphatase inhibitor cocktail (Sigma-Aldrich, St. Louis, MO, USA), and $1 \%$ protease inhibitor cocktail (Amresco, Solon, OH, USA). Further, protein concentrations were quantified utilizing a colorometric DC protein assay kit (BioRad, Hercules, California, USA). Further, a $4 \mathrm{X}$ Laemmli buffer $(20 \% \beta$ mercaptoethanol, $16 \%$ SDS, $40 \%$ glycerol, $0.01 \%$ bromophenol blue, and $0.25 \mathrm{M}$ Tris, $\mathrm{pH} 6.8$ ) was added to the samples, followed by denaturing at $50^{\circ} \mathrm{C}$ for 8 minutes. Equal amounts of proteins ( 15 ug per well) were loaded in each well of a $10 \%$ polyacrylamide SDS-PAGE gels (Bio-Rad, Hercules, CA, USA) and electrophoresed with a Tris-glycine running buffer at 200 volts for 45 minutes. Gels were then activated using a ChemiDoc ${ }^{\mathrm{TM}}$ MP imager (Bio-Rad, Hercules, CA, USA) and transferred to a $0.2 \mu \mathrm{m}$ nitrocellulose membranes (Bio- 
Rad Hercules, CA, USA) with the Trans-Blot ${ }^{\circledR}$ Turbo $^{\mathrm{TM}}$ Transfer System (Bio-Rad, Hercules, CA, USA) and total protein on the membranes were measured utilizing the ChemiDoc $^{\mathrm{TM}}$ MP imager. Following imaging, all membranes were blocked in Tris-buffered saline with $0.1 \%$ Tween-20 (TBS-T) with 5\% milk, with the exception of membranes detecting phosphorylated proteins, which were blocked in TBS-T with $5 \%$ bovine serum albumin (BSA) instead of $5 \%$ milk, for one hour on a tilting platform at room temperature. Following blocking, membranes were then incubated at $4{ }^{\circ} \mathrm{C}$ overnight with the following primary antibodies: Total OXPHOS Rodent WB Antibody Cocktail (ab110413, Abcam, Cambridge, UK; 1:1000), NF-kB p105/p50 (ab32360, Abcam, Cambridge, UK; 1:1000), NF-кB p65 (ab16502, Abcam Cambridge, UK; 1:1000), NF-кB p75 (108299, Abcam, Cambridge, UK; 1:1000), ІкB- $\alpha$ (ab32518, Abcam, Cambridge, UK; 1:500), Drp1 (ab156951, Abcam, Cambridge, UK; 1:200), Mfn1 (ab56889, Abcam, Cambridge, UK; 1:500), c-Abl (2862,
Cell signaling technology, Danvers, USA; 1:100), phospho-c-Abl (Tyr245) (2868, Cell signaling technology, Danvers, USA; 1:100), PGC-1 $\alpha$ (PA5-38022, Thermo Fisher Scientific, Massachusetts, USA; 1:500), CaMKII (M-176, Santa Cruz, Texas, USA; 1:500), Nrf2 (ab62352, Abcam, Cambridge, UK; 1:500), and TFAM (ab131607, Abcam, Cambridge, UK; 1:500). Following primary antibody incubation, all membranes were washed with TBS-T buffer (three times; fifteen minutes each) and then incubated with either goat anti-mouse, or anti-rabbit IgG (H+L) antibody (Jackson ImmunoResearch Laboratories, West Grove, PA, USA, 1:2000 dilution) prepared in TBS-T buffer with 5\% milk or BSA for one hour at $4{ }^{\circ} \mathrm{C}$. Later, membranes were washed with $1 \mathrm{X}$ TBS-T buffer (three times; fifteen minutes each) and subjected to enhanced chemiluminescence ECL, utilizing a clarity ECL kit (Bio-Rad, Hercules, CA, USA) for five minutes and then visualized by the ChemiDoc ${ }^{\mathrm{TM}}$ MP imager using Bio-Rad Image Lab software.
A

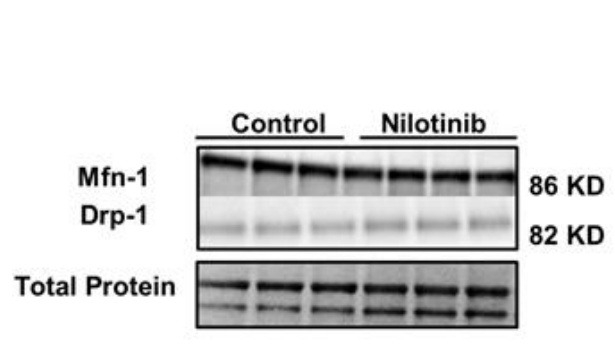

D

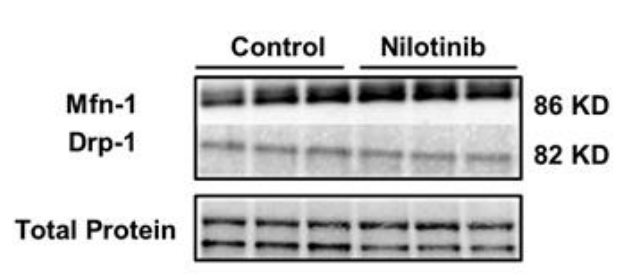

B

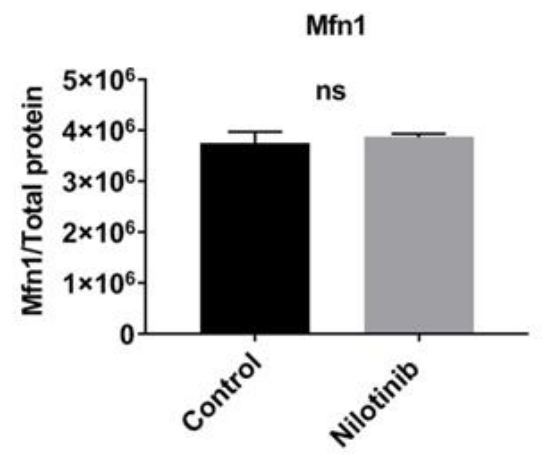

E

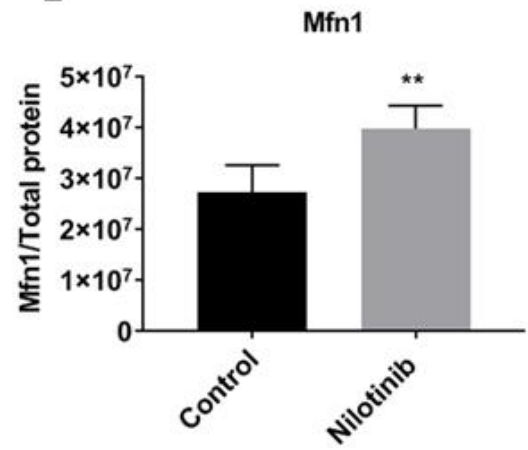

C

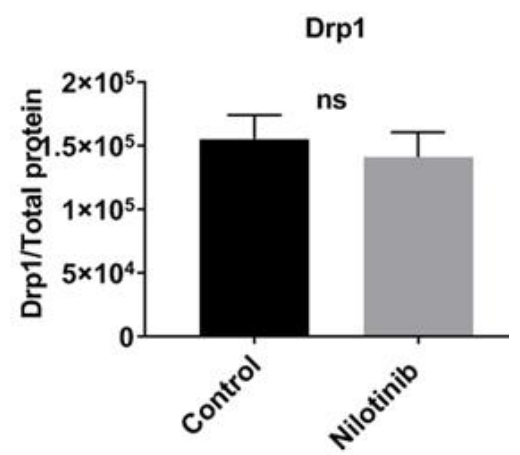

$\mathbf{F}$

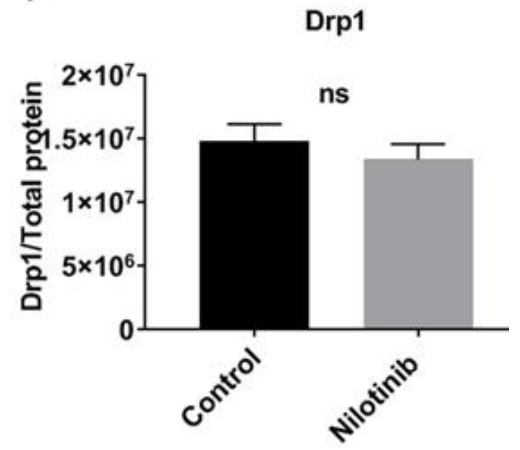

Figure 6. Nilotinib significantly altered the expression of Mfn1 in 3xTg-AD astroglia. Western blot experiments demonstrating relative levels of Mfn1 and Drp1 in C57BL/6-WT astroglia (A-C) and 3xTg astroglia (D-F) inthe presence and absence of 24 hrs. 100 $\mathrm{nM}$ nilotinib treatment. Relative quantification for protein levels of Mfn-1 and Drp-1 normalized to total protein. Results are expressed as mean $\pm \mathrm{SD}$ of $\mathrm{n}=6$ per group $(* * * \mathrm{P} \leq 0.001)$ analyzed by unpaired Student's t-test.

\section{Immunohistochemistry}

Immunohistochemistry was utilized to detect astroglia as described previously [8]. Briefly, cells were rehydrated using $1 \mathrm{X}$ TBS with $0.1 \%$ Tween 20 (TBS-T), for five minutes. Following rehydration, astroglia were fixed with 4\% paraformaldehyde in PBS ( $\mathrm{pH} 7.4$ ) for $10 \mathrm{~min}$ at room temperature. Further, antigen retrieval was performed for 
20-30 minutes in preheated $\left(80^{\circ} \mathrm{C}\right)$ citrate buffer $(\mathrm{PH} 8)$. All cells were then washed tree times with TBS-T (each time: 5 minutes each). Further, cells were then treated with anti-glial fibrillary acidic protein (GFAP) antibody (ab16997, abcam Cambridge, Massachusetts, USA, 1:100 dilution) to detect astrocytes combined with the EXPOSE mouse specific horseradish peroxidase/3-3-diamino- benzidine chromogen solution (HRP/DAB) detection immunohistochemistry kit (ab80436, Abcam, Cambridge, Massachusetts, USA). Fixed cells were observed with an inverted microscope (Nikon, Eclipse, TE200-U). Images captured with an infinity 2-1R CCD camera (Lumenera Corp., Ottawa, Ontario, Canada).
A

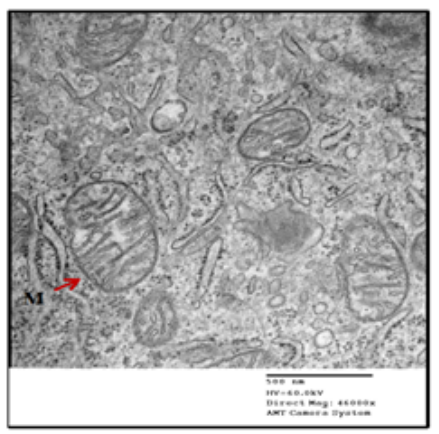

D

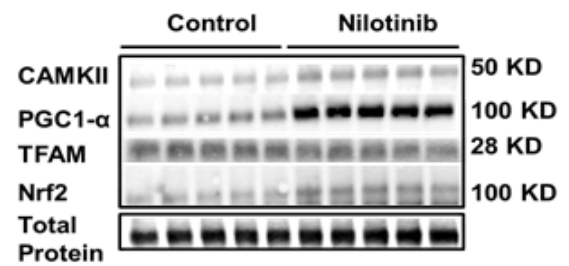

B

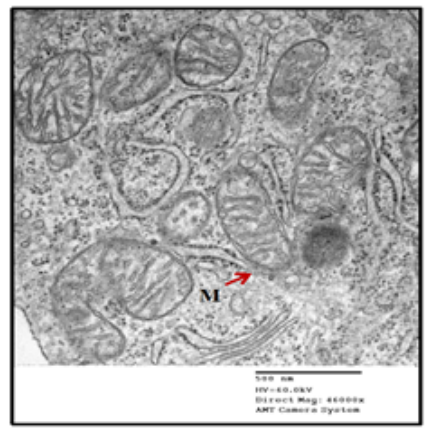

E
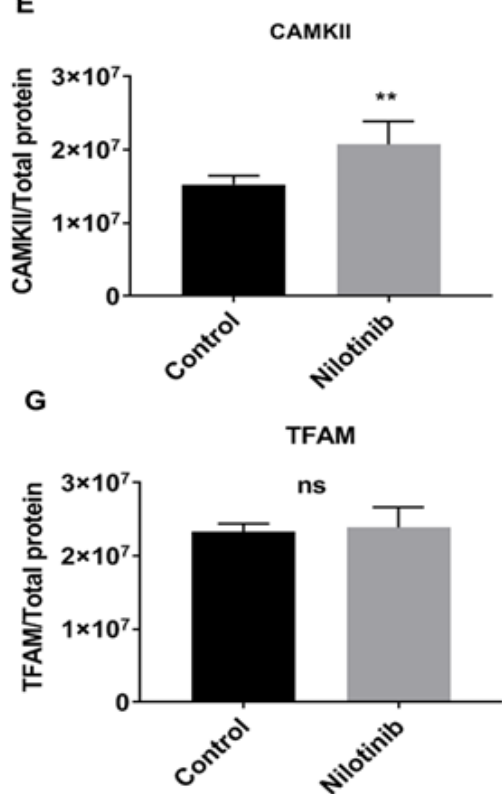

C

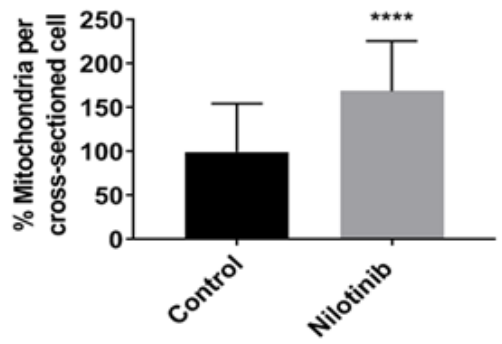

$\mathbf{F}$
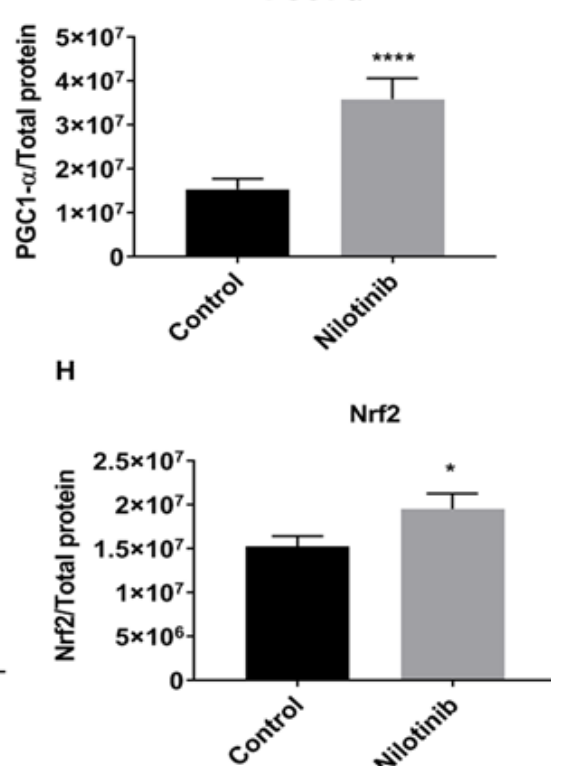

Figure 7. Nilotinib increased the number of mitochondria and mitochondrial biogenesis (CAMKII, PGC1- $\alpha$, and Nrf2) in 3xTg-AD astroglia. The numbers of mitochondria in 3xTg astroglia were compared in the presence and absence of nilotinib (100 $\mathrm{nM}$ ). Representative TEM image A showing the cell body of 3xTg astroglia. Representative TEM image B showing the cell body of the nilotinib-treated 3xTg-AD astroglia. (C) The number of mitochondria per cross-sectioned cell was counted (20 cells per group counted by TEM). Results are expressed as mean $\pm S D$ of $n=20$ per group ( $* * * P \leq 0.0001)$ analyzed by unpaired Student's t-test. M: mitochondria; Scale bars: $500 \mu \mathrm{m}$; Magnification: 46000x. (D-H) Western blot experiments demonstrating relative levels of CAMKII, PGC1- $\alpha$, TFAM, and Nrf2 in 3xTg-AD astroglia in the presence and absence of 24 hrs. $100 \mathrm{nM}$ nilotinib treatment. Relative quantification for protein levels of CAMKII, PGC1- $\alpha$, TFAM, and Nrf2 normalized to total protein. Results are expressed as mean \pm SD of $n=5$ per group $(*=p<0.05$ or $* *=p<0.01$ or $* * * *=p<0.0001)$ analyzed by unpaired Student's t-test.

\section{Immunofluorescence analysis}

Immunofluorescence was utilized to detect translocation of NF- $\kappa$ B subunits (p50, p65, p75, also called RelA, RelB, and c-Rel, respectively) in $3 \times \mathrm{Tg}$ astroglia. Briefly, astroglia were rehydrated with TBS-T, for five minutes. Following rehydration, cells were fixed with $4 \%$ paraformaldehyde in PBS ( $\mathrm{pH}$ 7.4) for $10 \mathrm{~min}$ at RT. Following the fixation procedure, antigen retrieval was performed for 30 minutes in preheated $\left(80{ }^{\circ} \mathrm{C}\right)$ citrate 
buffer. All cells were then washed with TBS-T (three times; 5 minutes each). Cells were incubated with blocking buffer ( $1 \%$ bovine serum albumin (BSA) in TBST) for 1 hour at RT. Cells were then incubated with primary antibodies: NF- $\kappa B$ p50 ab32360, Abcam, Cambridge, UK; 1:100; NF-кB p65: ab16502, Abcam Cambridge, UK; 1:100; and NF-кB p75: 108299, Abcam, Cambridge, UK; 1:100; anti-GFAP antibody (ab16997, abcam Cambridge, Massachusetts, USA; 1:100 dilution) to detect astroglia or Ionized calcium binding adaptor molecule 1 (Iba-1) (019-19741, wako, Saitama, Japan, 1:100 dilution) to detect microglia overnight at $4{ }^{\circ} \mathrm{C}$.
Further, cells were washed three times with TBS-T and incubated for $2 \mathrm{~h}$ at RT with an Alexa fluor $^{\mathrm{TM}} 488$ secondary antibody (1:500; Invitrogen, Carlsbad, CA). Further, cells were washed three times with TBS-T and were mounted using mounting medium with $4^{\prime}, 6-$ diamidino-2-phenylindole (DAPI). Positively stained cells were captured on a Carl Zeiss Axioscope-2 fluorescence microscope equipped with AxioVision3 software using 20X objective. The volume density of NF$\kappa \mathrm{B}$ subunits was quantified using ImageJ software (http://rsbweb.nih.gov/ij/).

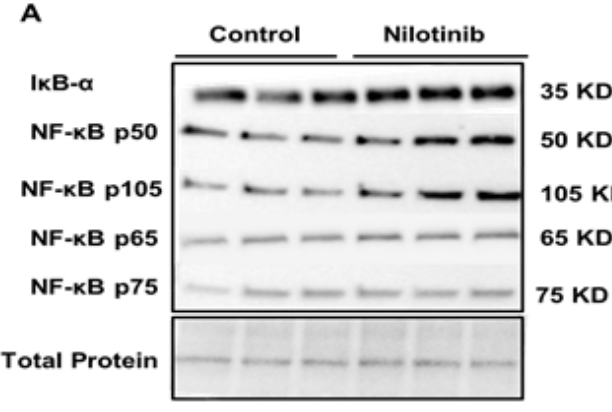

D

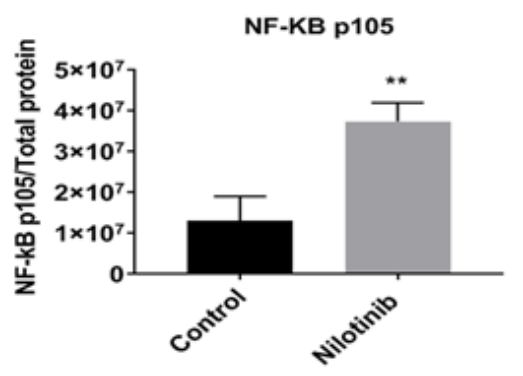

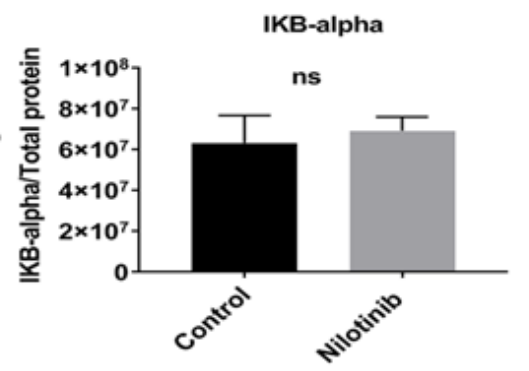

E

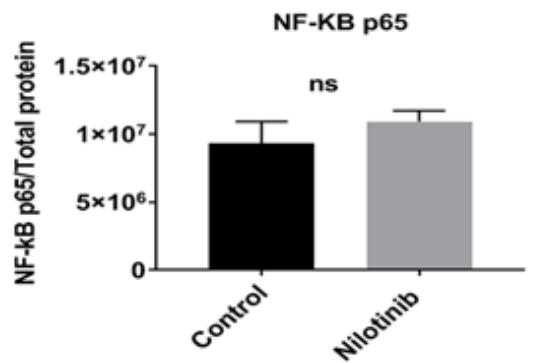

C
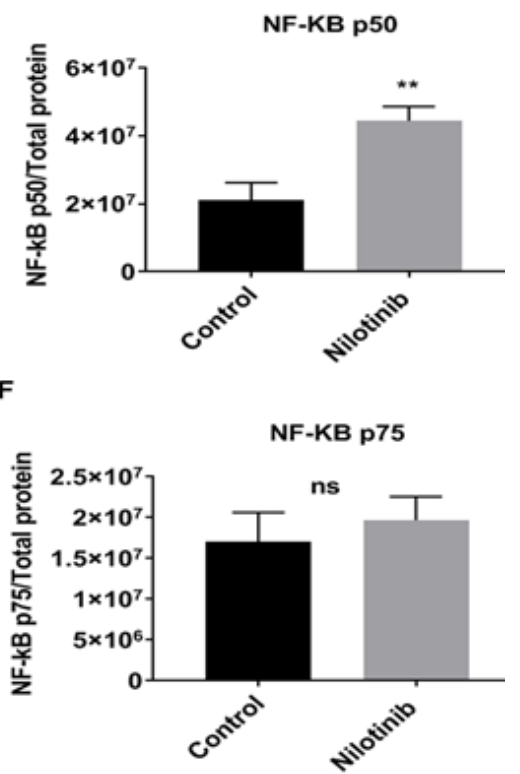

\section{G}

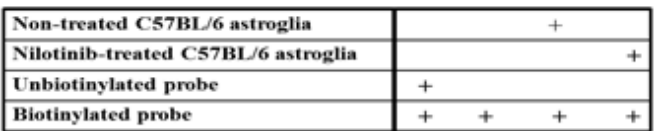

Biotinylated probe

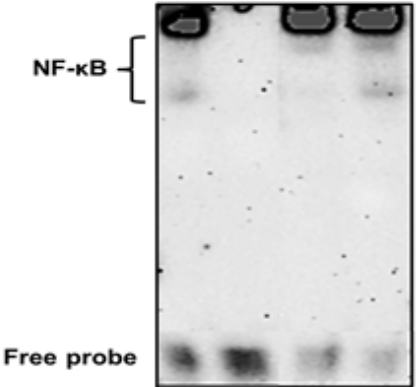

Figure 8. Nilotinib significantly increased the activation of NF-kB and expression of NF-kB p50/p105 subunits in C57BL/6-WT astroglia. (A) Western blot experiments demonstrating relative levels of NF-KB subunits (p50, p105, p65, and p75), and IкB- $\alpha$ in cultured cortical astroglia derived from C57BL/6 in the presence and absence of $24 \mathrm{hrs} .100 \mathrm{nM}$ nilotinib treatment. (B-F) Relative quantification for protein levels of NF-kB subunits (p50, p105, p65, and p75) and IKB- $\alpha$ normalized to total protein. (G) Nuclear extract derived from nilotinib-treated and non-treated C57BL/6-WT astroglia were assayed for NF-kB activation by EMSA using a biotinlabeled oligonucleotide encompassing the NF-KB consensus motif. Results are expressed as mean \pm SD of $n=6$ per group $(* * P \leq 0.01)$ analyzed by unpaired Student's t-test. 


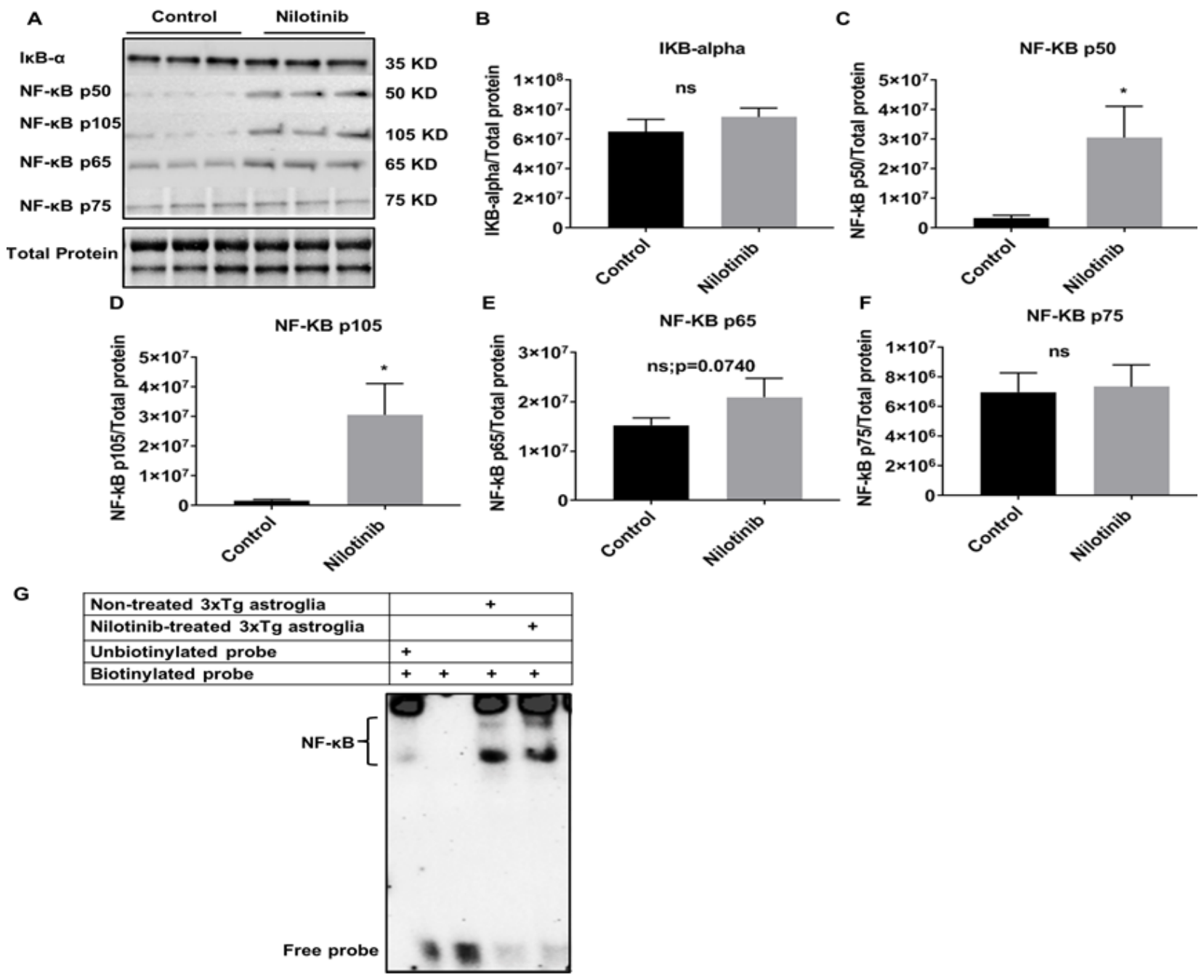

Figure 9. Nilotinib significantly increased the expression of NF-KB p50/p105 subunits and activation of NF-KB in 3xTg-AD astroglia. (A) Western blot experiments demonstrating relative levels of NF-KB subunits (p50, p105, p65, and p75), and IKB- $\alpha$ in cultured cortical astroglia derived from 3xTg in the presence and absence of $24 \mathrm{hrs} .100 \mathrm{nM}$ nilotinib treatment. (B-F) Relative quantification for protein levels of NF-KB subunits (p50, p105, p65, and p75) and IKB- $\alpha$ normalized to total protein. (G) Nuclear extract derived from nilotinibtreated and non-treated 3xTg-AD astroglia were assayed for NF-KB activation by EMSA using a biotinlabeled oligonucleotide encompassing the NF-KB consensus motif. Results are expressed as mean \pm SD of $n=6$ per group $(* P$ $\leq 0.05$ ) analyzed by unpaired Student's t-test.

\section{Transmission Electron Microscopy (TEM)}

Transmission electron microscopy (TEM) was used to study the fine structure of the mitochondria and to count the number of mitochondria, as described previously [60]. Briefly, astroglia derived from $3 \times \mathrm{Tg}$ mice were treated with/without nilotinib (100 nM) for 24 hours. After incubation, cells were washed with PBS and fixed 3 hours in $3 \% \mathrm{v} / \mathrm{v}$ glutaraldehyde in $0.1 \mathrm{M}$ Sorensen's buffer. Cells were again fixed in $1 \%$ osmium tetroxide in $0.1 \mathrm{M}$ Sorensen's phosphate buffer for two hours, and dehydrated in a $30 \%$ to $100 \%$ ethanol series and embedded with Epon resin and infiltrated for 4 days. Later, sections were polymerized at $60{ }^{\circ} \mathrm{C}$ for 30 hours; Images were collected with Morgagni 268D electron microscope (Philips, Netherlands).

\section{Statistical analysis}

Data was analyzed using two-tailed Student's t-tests (GraphPad Prism 6, GraphPad Software). A difference between or among groups was determined as statistically significant, if $* \mathrm{P} \leq 0.05, * * \mathrm{P} \leq 0.01, * * * \mathrm{P} \leq 0.001, * * * * \mathrm{P}$ $\leq 0.0001$. 


\section{RESULTS}

\section{Comparing the cellular bioenergetics profile between C57BL/6 and $3 x T g$ astroglia}

The mitochondrial oxygen consumption rate (OCR) was measured in astroglia derived from cortical brain regions from control (C57BL/6) and AD (3xTg) mice (Fig. 1A). At baseline levels, OCR in $3 \times \mathrm{Tg}$ astroglia was significantly decreased compared to control groups (Fig. 1B). Similarly, OCR associated with maximal respiration capacity was significantly decreased in $3 \times \mathrm{Tg}$ astroglia $v s$. controls (Fig. 1C). Consistent with changes in parameters associated with basal and maximal respiration, spare respiratory capacity was significantly lower in $3 x \mathrm{Tg}$ astroglia vs. controls (Fig. 1D). However, coupling efficiency was not significantly different in wells containing $3 \times \mathrm{Tg}$ astroglia and control cells (Fig. 1E).

\section{Effects of nilotinib in mitochondrial bioenergetics in C57BL/6 and $3 x T g$ astroglia}

To assess the effects of nilotinib on mitochondrial respiration, astroglia derived from C57BL/6 mice were cultured and treated with increasing concentrations of nilotinib $(0,1,10,100$, and $1000 \mathrm{nM})$ for 24 hours. Bioenergetic parameters of basal, maximal respiration, spare respiratory capacity, and coupling efficiency were not altered in C57BL/6 astroglia as a result of nilotinib treatment (Fig. 2A-E). To further determine if the OCR rates were reflected by similar alterations in cellular energy production, total ATP production was measured. ATP levels were not altered in C57BL/6 astroglia that were treated with or without nilotinib (Fig. 2F).
A

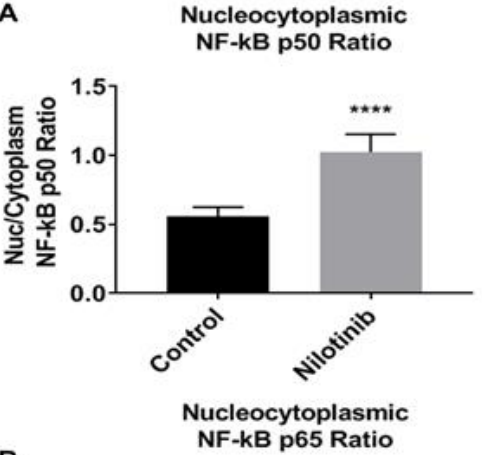

B

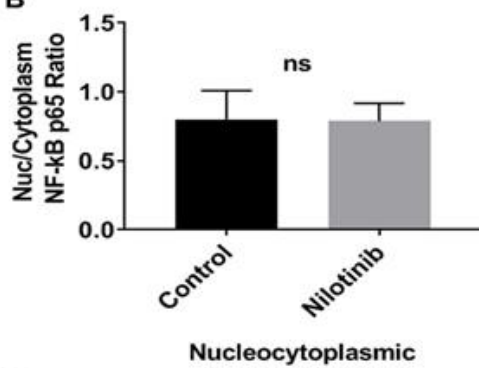

C

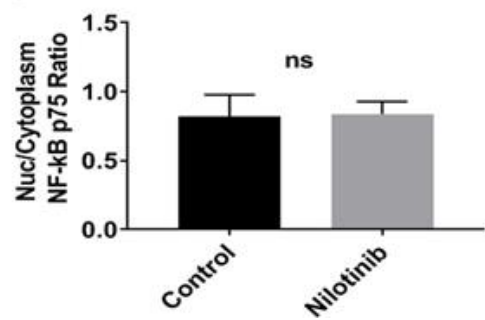

NF-kB p50
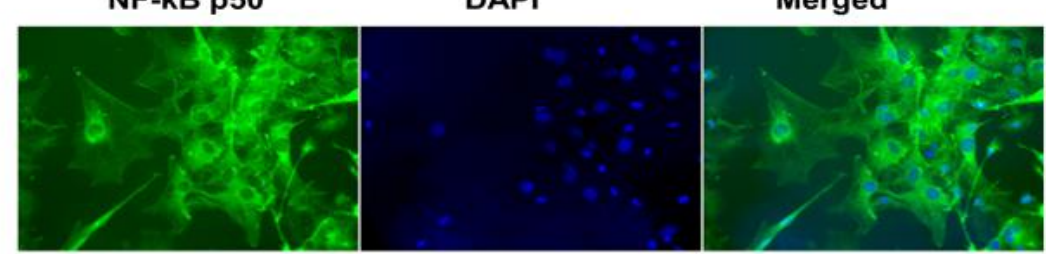

NF-kB p65
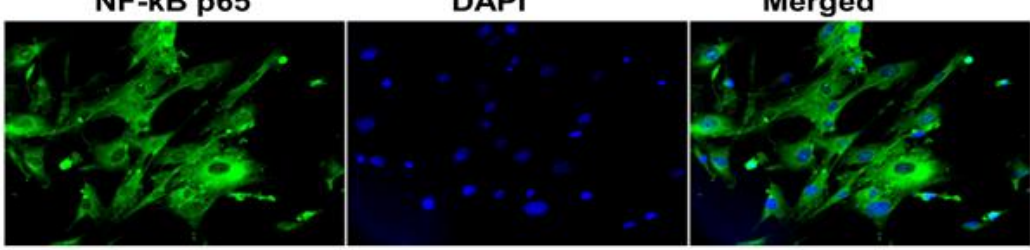

NF-kB p75

DAPI

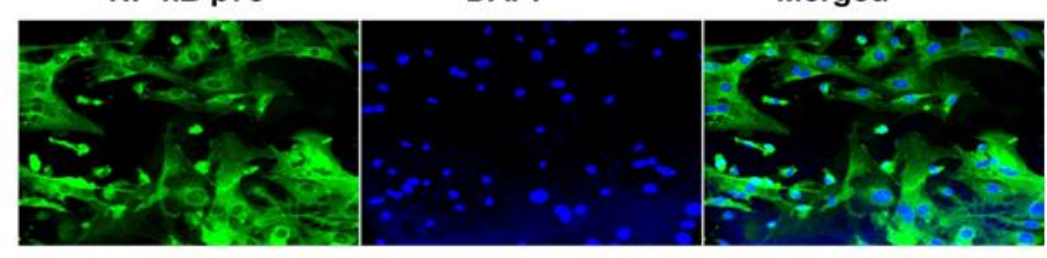

Figure 10. Nilotinib translocated the NF-kB p50 subunit into the nucleus of 3xTg-AD astroglia. Quantitative immunofluorescent nuclear/cytoplasmic ratios of NF- $\mathrm{kB}$ subunits (p50 (A), p65 (B), and p75 (C)) in 3xTg-AD astroglia. DAPI (blue) marks the nucleus. Images were captured at 100x magnification. Volume density of NF-kB subunits immunofluorescence was quantified using ImageJ software $(* * * * \mathrm{P} \leq 0.0001) ; \mathrm{n}=5$ per group analyzed by unpaired Student's t-test. 


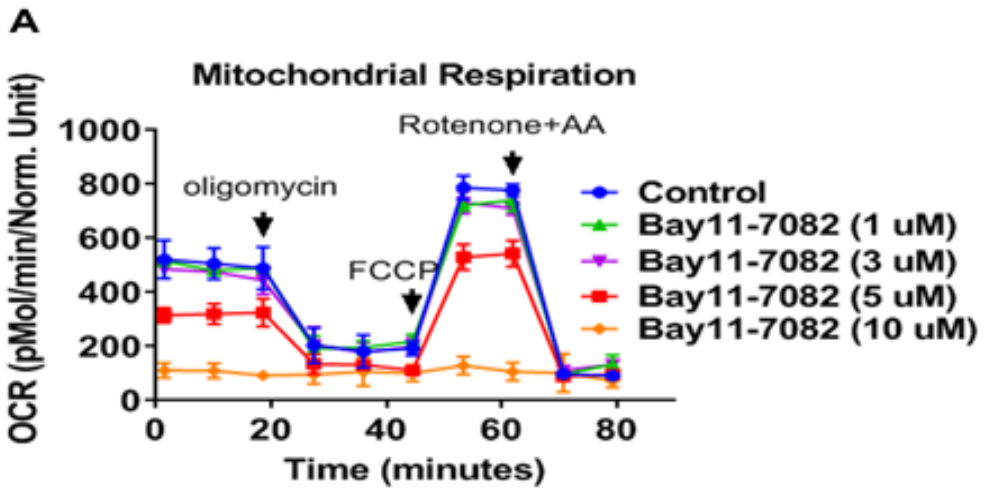

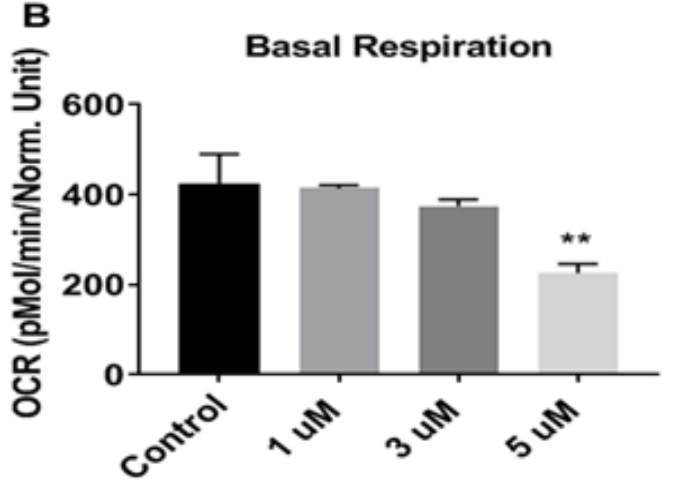

Bay11- 7082 Treatment

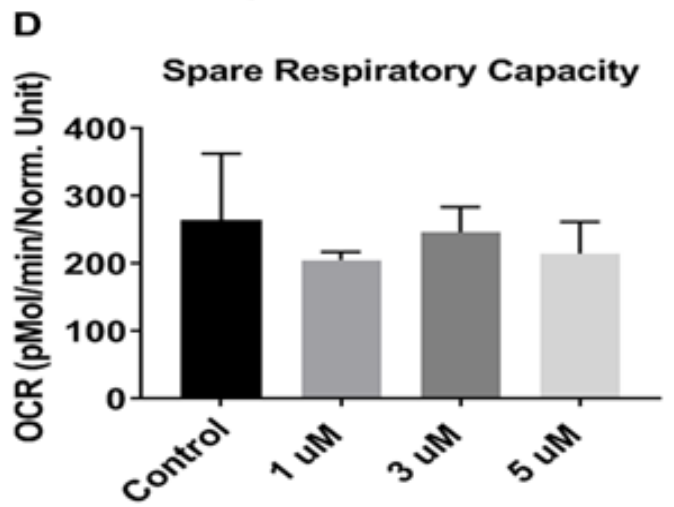

Bay11- 7082 Treatment

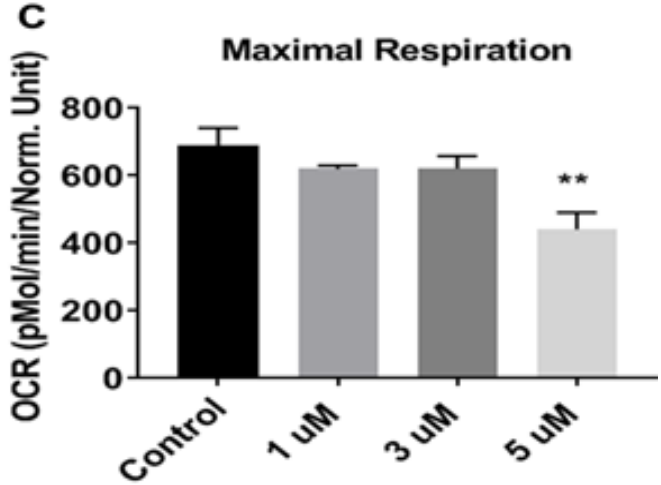

Bay11- 7082 Treatment

E

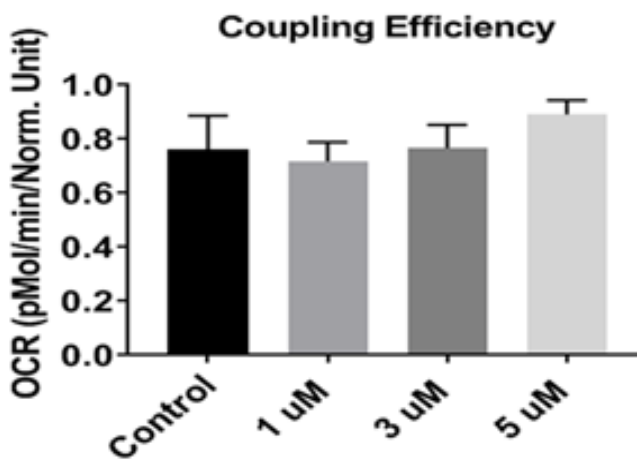

Bay11- 7082 Treatment

Figure 11. Bay11-7082 decreased mitochondrial respiration rates in 3xT-AD astroglia. (A) Kinetics graph indicating real-time OCR at baseline and after addition of oligomycin, FCCP, and rotenone/antimycin. The OCR was measured in 3xTg-AD astroglia utilizing the XF24 analyzer after 24 hours treatment with Bay11- 7082 (1, 3, 5, and $10 \mathrm{uM}$ ). (B) Basal respiration, (C) maximal respiration and (D) spare respiratory capacity, and $(\mathbf{E})$ coupling efficiency were calculated compared between control and treated cells. Data are mean \pm SD of $\mathrm{n}=5$ group $(* *=\mathrm{p}<0.01)$ analyzed by unpaired Student's t-test.

To assess the effect of nilotinib in the cellular bioenergetics profile of $\mathrm{AD}$, astroglia derived from $3 \times \mathrm{Tg}$ mice were cultured and treated with increasing concentrations of nilotinib $(0,1,10,100$, and $1000 \mathrm{nM})$ for 24 hours. Unlike C57BL/6 astroglia, mitochondrial OCR in 3xTg astroglia was enhanced significantly at 100 $\mathrm{nM}$ of nilotinib after 24 hours (Fig. 3A). At baseline, OCR in $3 \times \mathrm{Tg}$ astroglia in the presence of $100 \mathrm{nM}$ nilotinib was significantly increased as compared to non-treated cells (Fig. 3B). Additionally, bioenergetics parameters of maximal respiration rates as well as spare respiratory capacity were significantly increased 24 hours after nilotinib treatment (Fig. 3C-D). However, nilotinib did not affect the coupling efficiency (coupled respiration 
relative to basal levels) (Fig. 3E). To confirm OCR data, total ATP production was measured in $3 \mathrm{xTg}$ astroglia. ATP levels were significantly increased in nilotinibtreated $3 \times \mathrm{Tg}$ astroglia (Fig. 3F).

To further determine whether c-Abl levels are altered in response to the $\mathrm{c}-\mathrm{Abl}$ inhibitor, nilotinib, $3 \mathrm{xTg}$ and control astroglia were treated with $100 \mathrm{nM}$ nilotinib for 24 hours (Fig. 2G and 3G). Nilotinib did not lower total cAbl levels in control or $3 \times \mathrm{Tg}$ astroglia (Fig. $2 \mathrm{H}$ and $3 \mathrm{H}$ ). However, nilotinib (100 $\mathrm{nM})$ significantly decreased the levels of phosphorylated c-Abl in 3xTg astroglia, but not control astroglia (Fig. 2I and 3I).

\section{Effects of nilotinib in mitochondrial-associated proteins in $\mathrm{C57BL/6}$ and $3 x T g$ astroglia}

Similar to the OCR findings in C57BL/6 astroglia, Western blot data revealed that the expression levels of key mitochondrial subunit proteins (Complexes I-V) were not altered with nilotinib treatment (Fig. 4A-B). Additionally, activity of COX and CS in the nilotinibtreated group was not altered compared to that of controls (Fig. 4C).
A
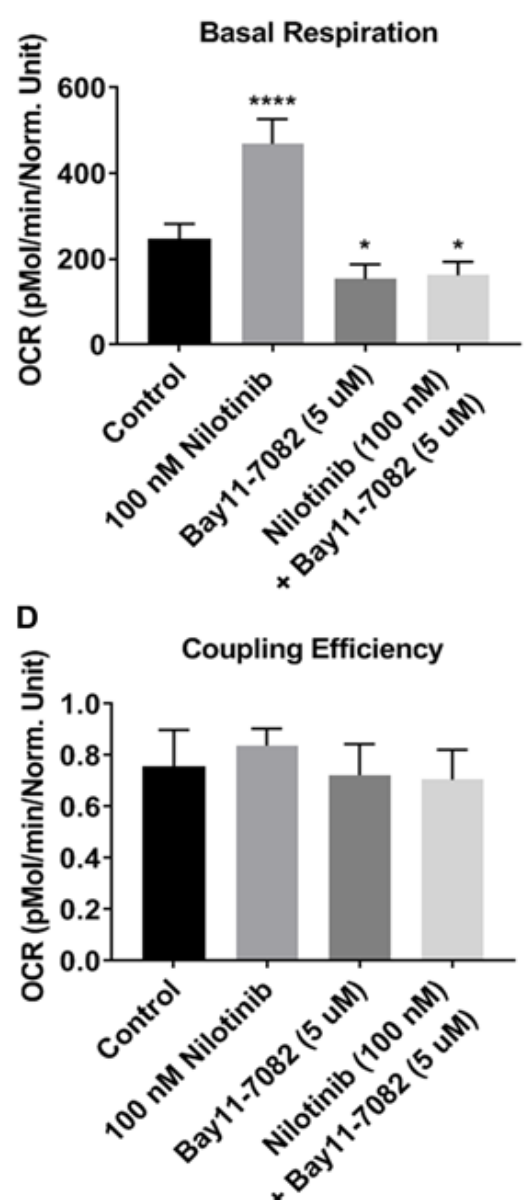

B

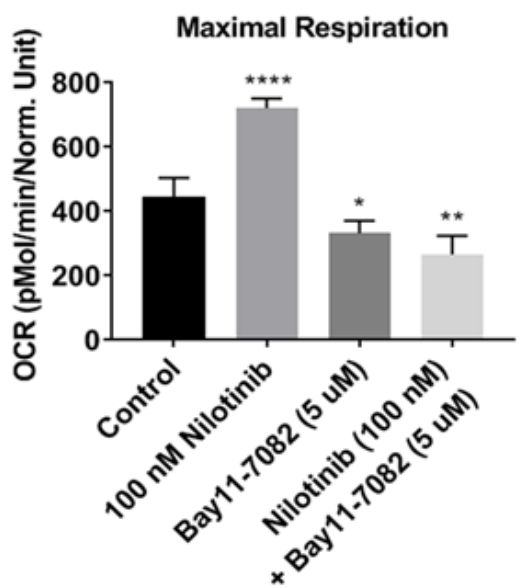

E

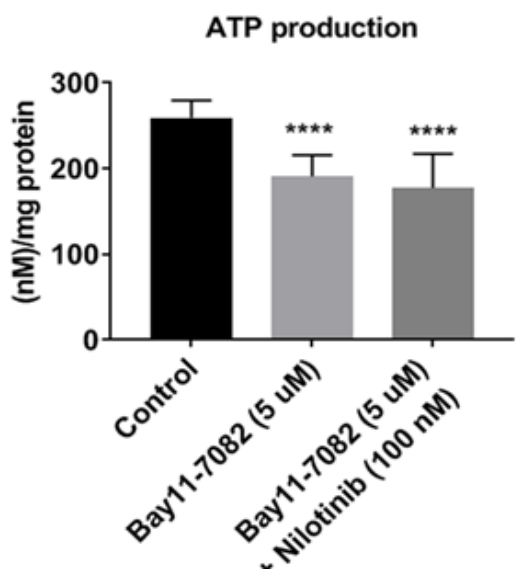

C

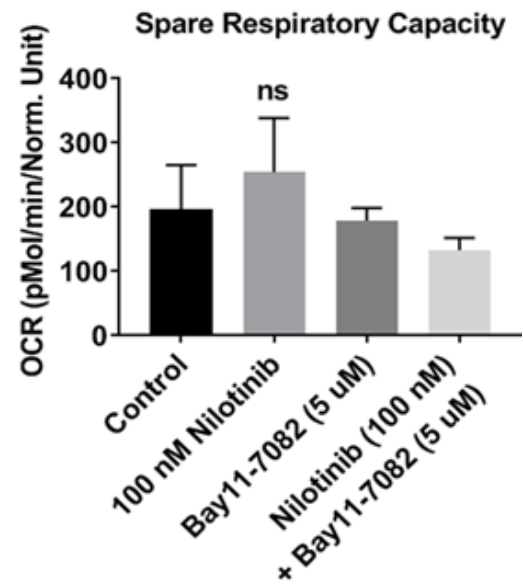

Figure 12. Nilotinib-induced enhancements in energy metabolism appear NF-kB-dependent, as demonstrated in 3xTg-AD astroglia. The OCR was measured in 3xTg-AD astroglia utilizing the XF24 analyzer after 24 hours treatment with nilotinib $(100 \mathrm{nM})$ or Bay11-7082 (5 uM) or co-treatment with nilotinib (100 nM) + Bay11- $7082(5 \mathrm{uM})$. (A) Basal respiration, (B) maximal respiration, (C) spare respiratory capacity, (D) coupling efficiency, and (E) ATP level were calculated compared between control and treated cells. Data are mean \pm SD of $n=5$ per group $(*=\mathrm{p}<0.05$ or $* *=\mathrm{p}<0.01$ or $* * *=\mathrm{p}<0.001$ or $* * * *=\mathrm{p}<0.0001)$ analyzed by unpaired Student's t-test.

Consistent with the mitochondrial OCR findings in $3 \times T g$ astroglia, Western blot results revealed a significant increase in the protein levels of NADH dehydrogenase beta sub-complex subunit 8 of Complex I, cytochrome b- c1 subunit 2 of Complex III, cytochrome c oxidase subunit 1 of Complex IV, as well as ATP synthase subunit alpha of Complex V in nilotinib-treated 3xTg astroglia $v s$. non-treated astroglia (Fig. 5A-B). The activity of CS was 
not altered as a function of nilotinib (Suppmentary Fig. 2). The activity of COX in the nilotinib-treated group was significantly increased compared to that of controls (Fig. 5C). However, the protein levels of Succinate dehydrogenase subunit B of Complex II were not found to be altered in nilotinib-treated $3 \times \mathrm{Tg}$ astroglia compared with non-treated ones (Fig. 5A-B).

To measure the effect of nilotinib in mitochondrial dynamics, the level of dynamin-related protein 1 (Drp1) and mitofusin 1 (Mfn1) proteins were measured by immunoblotting. Levels of Mfn1 and Drp1 were not significantly different as a function of nilotinib treatment in C57BL/6 astroglia (Fig. 6A-C), indicating that nilotinib did not induce changes in mitochondrial dynamics' proteins in C57BL/6 astroglia. As well, nilotinib did not alter the level of Drp1 from 3xTg astroglia; however, nilotinib significantly increased the level of Mfn 1 in $3 \times \mathrm{Tg}$ astroglia, indicating that nilotinib induces changes in mitochondrial mass (Fig. 6D-E). To further clarify the role of nilotinib on mitochondrial dynamics in $3 \times \mathrm{Tg}$ astroglia, we compared the number of mitochondria in nilotinib-treated vs. non-treated cells utilizing TEM. As shown in Fig. 7A-C, nilotinib significantly increased the number of mitochondria in $3 \times \mathrm{Tg}$ astroglia as compared to that of the non-treated group. To support the TEM data, we measured the effect of nilotinib in key regulators of mitochondrial biogenesis, including PGC- $1 \alpha$, CaMKII, Nrf2, and TFAM. The expression of PGC-1 $\alpha$, CaMKII, and Nrf2 in the nilotinib-treated 3xTg astroglia was significantly increased compared to that of controls (Fig. 7D-H). However, the protein level of TFAM was not found to be altered in nilotinib-treated $3 \times \mathrm{Tg}$ astroglia compared with non-treated cells (Fig. 7G).

\section{Effects of nilotinib in neuroinflammatory-associated proteins in C57BL/6 and $3 x$ Tg astroglia}

To further investigate the molecular mechanisms underpinning the enhanced mitochondrial function with nilotinib, expression of various neuroinflammatoryassociated proteins in C57BL/6 and 3xTg astroglia were semi-quantified with immunoblotting (Fig. 8A-F and Fig. 9A-F). Nilotinib significantly increased expression levels of NF- $\kappa$ B p50 and NF- $\kappa$ B p105 in C57BL/6 astroglia (Fig. $8 \mathrm{C}-\mathrm{E})$. However, the expression levels of IkB- $\alpha$ and NF$\kappa \mathrm{B}$ p75 in C57BL/6 astroglia were unaffected (Fig. 8B and $8 \mathrm{~F}$ ). Further, EMSA was used to verify the effect of nilotinib on NF- $\kappa B$ activation and binding. Nilotinib increased transcriptional activity of NF-kB in C57BL/6 astroglia (Fig. 8G).

In addition, nilotinib increased expression levels of $\mathrm{NF}-\kappa \mathrm{B}$ p50 and NF- $\kappa \mathrm{B}$ p105 subunits in $3 \times \mathrm{xTg}$ astroglia (Fig. 9C-D). In contrast, the expression levels of IкB- $\alpha$, NF- $\kappa B$ p65, and NF- $\kappa B$ p75 subunits in $3 \times T$ Tg astroglia were unaffected (Fig. 9B, 9E, and 9F). Further, EMSA data verify that nilotinib significantly increased transcriptional activity of NF- $\mathrm{KB}$ in $3 \times \mathrm{Tg}$ astroglia (Fig. 9G).

Stimulation with specific inducers activate NF- $\kappa B$ signaling pathways resulting in the translocation of NF$\kappa \mathrm{B}$ dimers to the nucleus to activate NF- $\kappa \mathrm{B}$ target genes [71]. In the current study, immunofluorescence (IF) was utilized to verify the effect of nilotinib on NF- $\mathrm{B}$ translocation. IF data in $3 \times \mathrm{Tg}$ astroglia indicated that nilotinib $(100 \mathrm{nM})$ treatment significantly translocated NF- $\kappa B$ p50 to the nucleus but had no effect on the

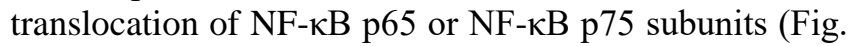
10A-C).

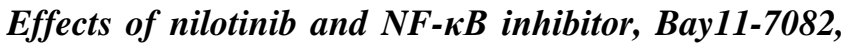 on mitochondrial respiration in 3xTg astroglia}

To investigate whether nilotinib increased mitochondrial respiration in $3 \mathrm{xTg}$ astroglia through the $\mathrm{NF}-\mathrm{kB}$ signaling pathway, astroglia were treated with either a NF- $\kappa \mathrm{B}$ inhibitor (Bay11-7082 (1, 3, 5, and $10 \mu \mathrm{M})$ ) alone, or cotreated with nilotinib $(100 \mathrm{nM})$ for 24 hours. The mitochondrial OCR in 3xTg astroglia was decreased significantly at $5 \mu \mathrm{M}$ of Bay11-7082 after 24 hours (Fig. 11A). At basal and maximal level, OCR in 3xTg astroglia in the presence of Bay11-7082 $(5 \mu \mathrm{M})$ was significantly decreased as compared to non-treated cells (Fig. 11B-C). Additionally, bioenergetics' parameters of spare respiratory capacity, as well as spare coupling efficiency, were unchanged after Bay11-7082 treatment (Fig. 11DE). Although Bay11-7082 decreased OCR level in 3xTg astroglia, co-treatment of Bay11-7082 $(5 \mu \mathrm{M})$ and nilotinib $(100 \mathrm{nM})$ did not compensate mitochondrial deficits (Fig. 12A-C). Spare respiratory and coupling efficiency were not affected with co-treatment of Bay117082 (5 uM) and nilotinib (100 nM) (Fig. 12D-E). To further determine if the mitochondrial respiration rates were reflected by similar alterations in cellular energy production, total ATP production was measured. ATP levels were significantly decreased in $3 \times \mathrm{Tg}$ astroglia that were treated with nilotinib or co-treated with Bay11-7082 (Fig. 12F).

\section{DISCUSSION}

We report, for the first time, the effects of nilotinib treatment on brain astroglia derived from the cortex of $3 \times T g-A D$ versus C57BL/6-WT mice. The results showed cortical astroglia from $3 \times \mathrm{xTg}$ mice exhibited significant declines in parameters of mitochondrial bioenergetics as compared to the control group. This study is the first to demonstrate increased mitochondrial function of $3 \mathrm{xTg}$ astroglia as a result of nilotinib treatment $(100 \mathrm{nM})$. Also, 
for the first time we provide evidence that nilotinib's benefit in mitochondria involves an NF-kB-dependent pathway. Nilotinib has been previously shown to induce apoptosis in cancer cells at micromolar rather than nanomolar concentrations [12, 72-75]. However, data from our study indicate that nilotinib is effective in $3 \times \mathrm{Tg}$ astroglia at nanomolar concentrations. Growing evidence suggests that mitochondrial dysfunction contributes to early events in the pathogenesis of $\mathrm{AD}[7,40,76,77]$. Therefore, the current study has important implications for the treatment of disorders affected by dysfunctional mitochondria, including AD.

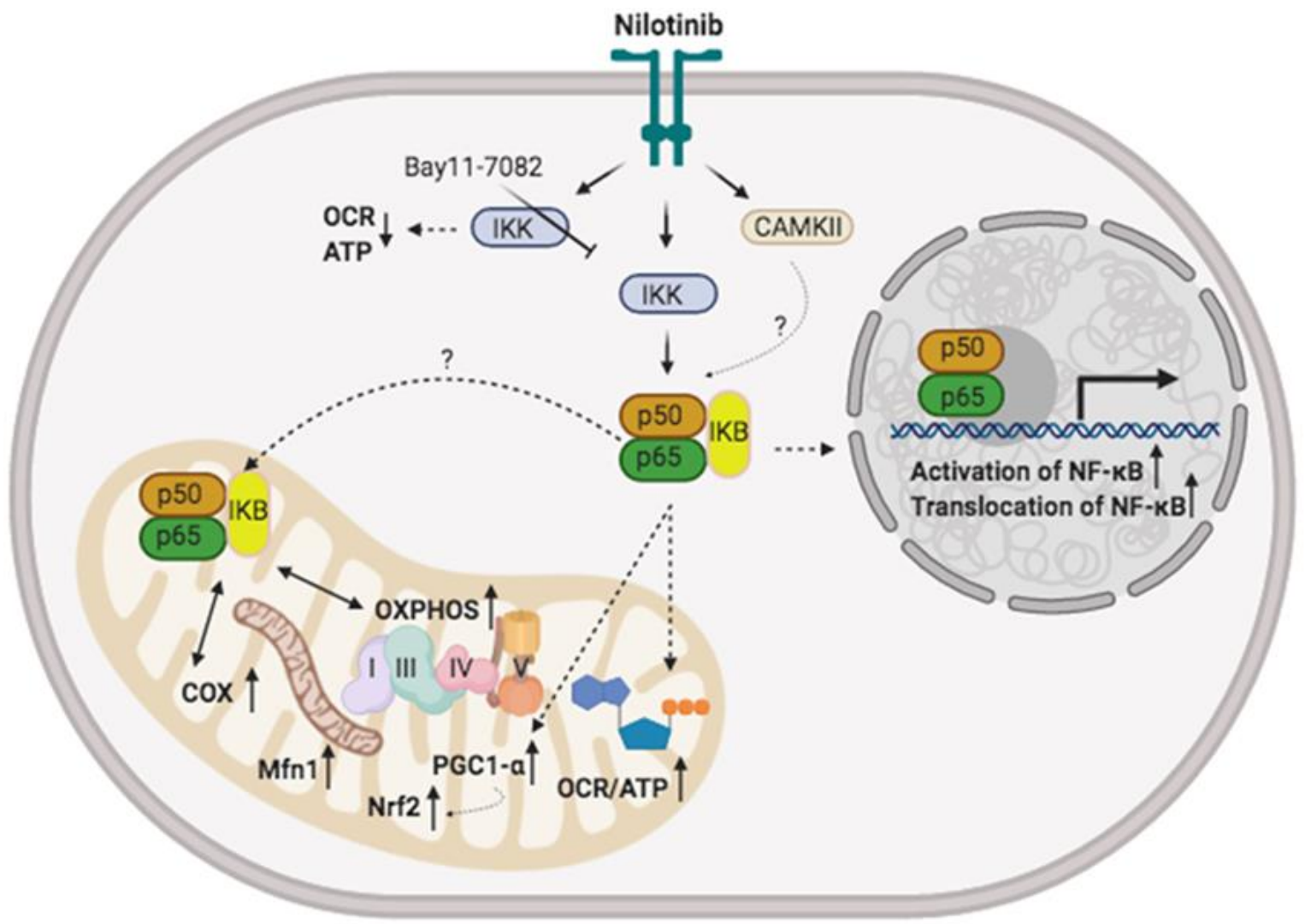

Figure 13. This putative pathway suggests that nilotinib improves mitochondrial function through nuclear factor $k$ B (NF-KB)-dependent signaling in 3xTg-AD astroglia. It is hypothesized that nilotinib activates CAMKII as well as a signal cascade resulting in degradation of the NF-KB subunit IKB. The NF-KB dimer then translocates from the cytoplasm to the nucleus where it binds to a DNA consensus sequence of target genes. It is also hypothesized that nilotinib triggers the NF-KB complex (downstream target of CAMKII) to move into the mitochondrion, where is thought to interact with OXPHOS genes that leads to bioenergetic improvement (ATP, oxygen consumption rate (OCR)), as well as an increase in the expression of mitochondrial complex proteins subunits (Complexes I, III, IV, and V), cytochrome c oxidase (COX), mitochondrial biogenesis (PGC1- $\alpha$ and Nrf2), and mitochondrial dynamics (Mfn1). Findings from our current study importantly show that mitochondrial OCR and ATP levels were significantly reduced in the presence of the IKK inhibitor (Bay11-7082). This figure was developed using the BioRender online software tool.

Different types of brain cells have unique features of mitochondrial function, and display explicit roles related to their metabolic function. A previous proteomic study designates that the mitochondrial function and morphology is various in different types of brain cells [78]. A better understanding of mitochondrial impairment in $\mathrm{AD}$ requires a cell-type specific approach. Although astroglia and neurons are linked in their energy metabolism, they are still different types of brain cell that utilize a very different metabolic profile. Neuronal cells, during periods of enhanced activity, produce the toxic fatty acids (FA) that are transported into astroglia, which can be detoxified in mitochondria instead of being dealt with in neurons [79]. Unlike astroglia, neuronal cells have a restricted capacity to up-regulate glycolysis or to counteract oxidative damage [80, 81]. Additionally, neurons rely on OXPHOS to meet their energy requirements; therefore, mitochondrial dysfunction leads 
to increased generation of reactive oxygen species (ROS), energy failure, and ultimately neuronal cell death. Under environmental and cellular stress conditions, astroglia have their distinct metabolic reprogramming mediated via mitochondrial dynamics, which determine the inflammatory features of glia $[82,83]$. Other studies show that metabolic activity in astroglia may actually increase with age [84]. Increased metabolic activity in astroglia was linked with an age-dependent increase in inflammatory pathways, including NF- $\mathrm{kB}$ signaling [85, 86]. Further, inflammatory cytokines in astroglia triggered OXPHOS as well as mitochondrial biogenesis [84]. Human astroglia infected with human immunodeficiency virus (HIV) displayed mitochondrial damage, severe inflammation, and ultimately cell death. On the other hand, HIV-infected astroglia modulates inflammatory responses and regulation of mitochondrial dynamics followed by mitophagy [87]. These opposed scenarios with regard to modulation of mitochondrial dynamics regulate cell viability. Investigators have speculated that mitophagy in HIV-infected astroglia may reduce inflammation via removing damaged mitochondria that leads to cell viability [60, 87]. Interestingly, Lonskaya et al. show that nilotinib improves autophagic machinery, leading to $A \beta$ clearance in transgenic amyloid precursor protein (APP) mice, thus suggesting therapeutic benefits for AD [88]. A current study also shows that mitochondrial OCR was significantly lower in AD astroglia as compared to control and nilotinib increased mitochondrial function and inflammatory responses. It has also been suggested that the astroglia response to nilotinib leads to increased inflammatory responses that support the functionality switch of astroglia to increase metabolic activity for energy support. Also, nilotinib increases the expression of mitochondrial dynamics, which might act as a compensatory mechanism to preserve energy by balancing proteins from one healthy mitochondrion to another mitochondrion that might be damaged.

The cumulative evidence has reported that mitochondrial dysfunction plays an important role in neurodegenerative disorders including $\mathrm{AD}$. The present study demonstrates that nilotinib regulates brain bioenergetics in $3 \times \mathrm{Tg}$ astroglia. Our data show that nilotinib treatment of $3 \times \mathrm{Tg}$ astroglia increased the mitochondrial respiration rate, ATP levels, and the expression of mitochondrial complex subunit proteins. Metabolic investigations into synaptic mitochondia show that a $\sim 25 \%$ reduction in Complex I activity and $>70 \%$ reduction in Complexes III and IV activity results in depletion of ATP and OCR levels [89, 90]. Therefore, a significant portion of oxidative phosphorylation in synaptic mitochondria is regulated via the activity of Complex I and Complexes (III and IV), respectively. In the current study, nilotinib increased the expression of mitochondrial subunits (Complexes I and III-V) that may lead to increased newly-generated synapses.

A decrease in mitochondrial respiration rate in $3 \times \mathrm{Tg}$ cells is also consistent with literature indicating mitochondrial function impairment in $3 \times \mathrm{Tg}$ mouse models [91, 92]. Previously, our laboratory identified significant decreases in brain glucose uptake rates and decreases in the activity of the terminal mitochondrial enzyme (COX or Complex IV) in 3xTg cortex [8]. In the present study, nilotinib increased the activity of COX (Complex IV) in 3xTg astroglia. These results suggest that nilotinib improves the function of respiratory complexes in $3 \times T$ astroglia. However, nilotinib had no effect on protein levels of mitochondrial complex subunits in control astroglia. Together, these data indicate that nilotinib improves mitochondrial function under pathological states.

Additionally, increase in mitochondrial oxidative metabolism is paralleled by increase in the level of COX suggesting an enhanced mitochondrial biogenesis [93]. Moreover, several reports link mitochondrial bioenergetics to mitochondrial dynamics [94-96]. Additionally, impaired mitochondrial function is consistent with altered mitochondrial dynamics in $\mathrm{AD}$ [49, 77, 97-101]. Some studies report increased levels of mitochondrial fission protein Drp1 and decreased levels of mitochondrial fusion protein Mfn2 in AD brain [102, 103], which lead to loss of respiratory capacity, mitochondrial damage and thus a decreased energy metabolism [5, 104, 105]. Other studies report that mitochondrial dynamic inhibitors reduced mitochondrial metabolism as well as the activity of the ETC, which leads to neurodegeneration in AD [100, 105-108]. The Mfnmediated fusion is an important marker to maintain proper ETC function and maintain OXPHOS. In fact, a deficiency in mitochondrial fusion has been revealed to result in mitochondrial dysfunction [109]. For example, double knock out Mfn1/2 mice show reduced number of mtDNA, OCR, and complex II activity [110]. Our current study reports that nilotinib increased the level of mitochondrial fusion marker (Mfn1), which would ascribe specific features to mitochondria for various cellular metabolic procedures, such as up regulation of mitochondrial bioenergetics (OCR, ATP) and OXPHOS.

Mitochondrial fusion has been proposed to provide a new strategy for treating mitochondria-related disorders, such as neurodegenerative disorders [111]. Even mutantDNA mitochondria can fuse with healthy mitochondria of the same cell, which allows WT-DNA mitochondria to compensate for defects in mutant-DNA mitochondria by sharing RNA and/or protein components [112, 113]. Additionally, mitochondrial fusion can rescue two mutant mitochondria by cross-complementation to one another 
[114]. It is also suggested that mitochondrial fusion functions as a protective response against stress conditions, carried out by the main participants in the mitochondrial fusion. Disruption in mitochondrial fusion markers (Mfn1/Mfn2) caused severe reduction of mitochondrial DNA (mtDNA) levels [110]. Additionally, mitochondrial fusion disorder significantly decreases mitochondrial function and ultimately causes death in a mouse model with high levels of mtDNA mutations, proposing a protective role for Mfn $1 / 2$ against mtDNA mutations [110]. Overall, mitochondrial fusion can lead to compensation of damage, thus rescuing damaged organelles and failure of mitochondrial fusion may lead to neurodegenerative diseases. The current study shows that nilotinib increased the expression of mitochondrial fusion. It is suggested that mitochondrial fusion acts as a compensatory mechanism to preserve energy by balancing proteins from one healthy mitochondrion to another, which might be damaged. Therefore, mitochondrial fusion may rescue damaged organelles and create a pool of healthy mitochondria by increasing fusion regularity without compromising the mitophagy of dysfunctional mitochondria [115]. The current study suggests that Mfn1 is compensating for an increase in mitochondrial biogenesis. These findings propose that regulation of mitochondrial dynamics and biogenesis signaling may indicate a new mitochondria-targeted therapeutic strategy for AD.

Emerging evidence has also revealed that mitochondrial dysfunction triggers inflammation [116]. Among a number of different transcription factors that are involved in the inflammation NF- $\mathrm{BB}$ is a key inflammatory regulator with activation in glia following brain injury or infection [117-119]. Several studies reported that NF- $\kappa \mathrm{B}$ controls inflammation in astroglia [120-122]. Additionally, the activity of NF- $\mathrm{KB}$ has been reported in glia isolated from $\mathrm{AD}$ rodent models, a Huntington's disease mouse model, and the spinal cord of patients with amyotrophic lateral sclerosis (ALS) [123125]. Also, glial NF- $\kappa B$ is associated with the pathology of neurodegenerative disorders such as AD [126]. The $\mathrm{NF}-\kappa \mathrm{B}$ pathway was activated in glia cultures in response to $A \beta$ treatment, which leads to increased expression of inflammatory cytokines such as interleukin-6 and interleukin-1 beta, and tumor necrosis factor $\alpha(\mathrm{TNF} \alpha)$ [84, 127-129]. Jiang and Cadenas 2014 found that increased inflammation triggers mitochondrial OXPHOS in astroglia [84]. These findings are consistent with our study, while nilotinib increases the expression of inflammatory marker (NF- $\kappa \mathrm{B})$ and OXPHOS. These data suggest NF- $\mathrm{KB}$ might play a compensatory role and can have beneficial effects in preserving brain health through an immune response. It is also important to consider NF$\mathrm{\kappa B}$ is not only involved in inflammation, but also plays a critical role in learning and memory formation [130-132]. Therefore, our finding suggests that up regulation of NF$\kappa \mathrm{B}$ via nilotinib might lead to memory improvement. Further research examining the effects of nilotinib in improving memory in $\mathrm{AD}$ mice is required.

Both mitochondrial dysfunction and neuroinflammation play critical roles in $\mathrm{AD}$ progression; However, molecular mechanisms underpinning enhanced mitochondrial function with nilotinib in astroglia are lacking. NF- $\kappa \mathrm{B}$ regulates energy metabolism and metabolic activity by upregulating mitochondrial respiration in cancer cells [53]. Nevertheless, how NF- $\kappa B$ controls mitochondrial function in $\mathrm{AD}$ brain cells is not understood [57]. To assess whether energy metabolism is enhanced by nilotinib through NF- $\mathrm{BB}$ associated pathways, $3 \times \mathrm{Tg}$ astroglia were treated with nilotinib alone or with Bay11-7082, an NF-kB inhibitor. Mitochondrial OCR levels were reduced in the presence of Bay11-7082; however, co-treatment of Bay11-7082 and nilotinib did not compensate for any mitochondrial deficits. These findings suggest that nilotinib could trigger mitochondrial function through an NF- $\mathrm{kB}$-dependent signaling pathway.

Furthermore, immunofluorescence confirmed that the NF- $\mathrm{kB}$ p50 subunit is translocated from the cytoplasm to the nucleus in nilotinib-treated $3 \times \mathrm{Tg}$ astroglia, showing that nilotinib initiates the transcriptional induction of NF$\kappa \mathrm{B}$-inflammatory signaling. Moreover, immunoblotting and EMSA demonstrated that nilotinib increased transcriptional activity of NF- $\kappa \mathrm{B}$ in $3 \times \mathrm{Tg}$ astroglia, which might be explained by increased NF- $\kappa \mathrm{B}$ nuclear translocation under nilotinib treatment. These findings indicate that the mechanism underlying the effect of nilotinib on cellular respiration involves an NF- $\mathrm{kB}-$ dependent pathway.

Several studies show that NF- $\mathrm{BB}$ has been specially linked to CaMKII activation [133, 134]. CaMKII plays critical roles in regulating inflammation as well as various mitochondrial functions, such as mitochondrial biogenesis $[92,135]$. An increase in CaMKII expression, in the presence of increased $\mathrm{NF}-\kappa \mathrm{B}$ transcriptional activity, as found here with nilotinib in $3 \times \mathrm{Tg}$ astroglia, is also consistent with literature indicating that CaMKII (upstream target) is required for NF- $\mathrm{KB}$ activation [136]. PGC-1 $\alpha$, a downstream target of CaMKII that has been implicated in mitochondrial biogenesis, was significantly increased as a function of nilotinib. The PGC- $1 \alpha$ is involved in $\mathrm{AD}$ pathogenesis and upregulation of PGC- $1 \alpha$ improves mitochondrial biogenesis through induction of transcription factor $\mathrm{Nrf} 2$, which is linked to NF- $\mathrm{BB}$ in pathological conditions [137-139]. The current study found upregulation of PGC- $1 \alpha$, in nilotinib-treated $3 \times \mathrm{Tg}$ astroglia, consistent with increased Nrf2 (downstream target of PGC-1 $\alpha$ ), which is a key modulator of mitochondrial metabolism and biogenesis [140-142]. 
These findings are consistent with previous studies indicating a role of Nrf2 in inflammation, mitochondrial biogenesis and bioenergetics and its interaction with PGC-1 $\alpha$ in the context of neurodegeneration [64, 143]. Overall, our study suggests that nilotinib may increase the number of mitochondria through a CaMKII- PGC- $1 \alpha-$ $\mathrm{Nrf} 2$ pathway, which is influenced by NF- $\mathrm{BB}$ dynamics in $3 \times \mathrm{Tg}$ astroglia.

\section{Conclusions}

Emerging evidence suggests that defects in mitochondrial function are associated with bioenergetic deficiency and neuroinflammation, and could serve as early biomarkers of $\mathrm{AD}$. The present results have important implications for treatment of disorders with mitochondrial dysfunction including $\mathrm{AD}$. The major finding of this study is that nilotinib treatment stimulated oxidative phosphorylation in $3 \times \mathrm{Tg}$ astroglia with upregulation of mitochondrial complex proteins subunits and COX activity. Additionally, nilotinib increases mitochondrial function and dynamics through altered CaMKII-PGC- $1 \alpha-\mathrm{Nrf} 2$ pathway activity that are involved in the development of neurodegeneration. Nilotinib also increased mitochondrial function via the NF- $\mathrm{kB}$ signaling pathway. Collectively, these results contribute to our understanding of the effects of nilotinib on regulating brain mitochondrial bioenergetics and biogenesis (Fig. 13).

\section{Acknowledgments}

We gratefully acknowledge the Research Manitoba Fellowship to Dr. Adlimoghaddam (Grant No: 1913), and support from the St. Boniface Hospital Research Foundation (Grant Nos.1406-3216 and 1410-3216), the Canadian Institute of Health Research (CIHR; Grant No. PJT-162144), the Alzheimer's Society of Manitoba, the Honourable Douglas and Patricia Everett, Royal Canadian Properties Limited Endowment Fund (Grant No. 1403-3131) to Dr. Albensi. Dr. Albensi also holds the Honourable Douglas and Patricia Everett and Royal Canadian Properties Limited Endowment Fund Chair and the Manitoba Dementia Research Chair (funded by the Alzheimer's Soc. of Manitoba \& Research Manitoba). He is also a Research Affiliate of the Centre on Aging, and a scientist at the Children's Hospital Research Inst. of Manitoba (CHRIM) at the University of Manitoba. Special thanks are given to Mr. Kyle M Fontaine for reviewing our manuscript. Thanks to Dr. Klonisch for interpreting the TEM data. Thanks to Ms. Marina Mostafizar and Ms. Claudia Perez for helping with the euthanization of mice. Thanks to Dr. Paul Fernyhough for allowing us to access and use his equipment (Seahorse XF24 Analyzer and fluorescence microscope).

\section{Conflict of interest}

The authors declare no conflict of interest.

\section{Supplementary Materials}

The Supplemenantry data can be found online at: www.aginganddisease.org/EN/10.14336/AD.2020.0910.

\section{References}

[1] McKeith I, Cummings J (2005). Behavioural changes and psychological symptoms in dementia disorders. Lancet Neurol, 4:735-742.

[2] Glabe CC (2005). Amyloid accumulation and pathogensis of Alzheimer's disease: significance of monomeric, oligomeric and fibrillar Abeta. Subcell Biochem, 38:167-177.

[3] Hardy J, Selkoe DJ (2002). The amyloid hypothesis of Alzheimer's disease: progress and problems on the road to therapeutics. Science, 297:353-356.

[4] Cardoso S, Seica RM, Moreira PI (2017). Mitochondria as a target for neuroprotection: implications for Alzheimer s disease. Expert Rev Neurother, 17:77-91.

[5] Cadonic C, Sabbir MG, Albensi BC (2016). Mechanisms of Mitochondrial Dysfunction in Alzheimer's Disease. Mol Neurobiol, 53:6078-6090.

[6] Correia SC, Santos RX, Cardoso S, Carvalho C, Candeias E, Duarte AI, et al. (2012). Alzheimer disease as a vascular disorder: where do mitochondria fit? Exp Gerontol, 47:878-886.

[7] Aliev G, Palacios HH, Walrafen B, Lipsitt AE, Obrenovich ME, Morales L (2009). Brain mitochondria as a primary target in the development of treatment strategies for Alzheimer disease. Int $\mathrm{J}$ Biochem Cell Biol, 41:1989-2004.

[8] Adlimoghaddam A, Snow WM, Stortz G, Perez C, Djordjevic J, Goertzen AL, et al. (2019). Regional hypometabolism in the $3 \times \mathrm{Tg}$ mouse model of Alzheimer's disease. Neurobiol Dis, 127:264-277.

[9] Hedskog L, Zhang S, Ankarcrona M (2012). Strategic role for mitochondria in Alzheimer's disease and cancer. Antioxid Redox Signal, 16:1476-1491.

[10] Pagan F, Hebron M, Valadez EH, Torres-Yaghi Y, Huang X, Mills RR, et al. (2016). Nilotinib Effects in Parkinson's disease and Dementia with Lewy bodies. J Parkinsons Dis, 6:503-517.

[11] Lonskaya I, Desforges NM, Hebron ML, Moussa CE (2013). Ubiquitination increases parkin activity to promote autophagic alpha-synuclein clearance. PLoS One, 8:e83914.

[12] Deremer DL, Ustun C, Natarajan K (2008). Nilotinib: a second-generation tyrosine kinase inhibitor for the treatment of chronic myelogenous leukemia. Clin Ther, 30:1956-1975.

[13] Slupianek A, Poplawski T, Jozwiakowski SK, Cramer K, Pytel D, Stoczynska E, et al. (2011). BCR/ABL stimulates WRN to promote survival and genomic 
instability. Cancer Res, 71:842-851.

[14] Hebron ML, Lonskaya I, Moussa CE (2013). Nilotinib reverses loss of dopamine neurons and improves motor behavior via autophagic degradation of alphasynuclein in Parkinson's disease models. Hum Mol Genet, 22:3315-3328.

[15] Hebron ML, Lonskaya I, Olopade P, Selby ST, Pagan F, Moussa CE (2014). Tyrosine Kinase Inhibition Regulates Early Systemic Immune Changes and Modulates the Neuroimmune Response in alphaSynucleinopathy. J Clin Cell Immunol, 5:259.

[16] Hebron ML, Lonskaya I, Moussa CE (2013). Tyrosine kinase inhibition facilitates autophagic SNCA/alphasynuclein clearance. Autophagy, 9:1249-1250.

[17] Soverini S, Martinelli G, Rosti G, Iacobucci I, Baccarani M (2012). Advances in treatment of chronic myeloid leukemia with tyrosine kinase inhibitors: the evolving role of Bcr-Abl mutations and mutational analysis. Pharmacogenomics, 13:1271-1284.

[18] Turner RS, Hebron ML, Lawler A, Mundel EE, Yusuf N, Starr JN, et al. (2020). Nilotinib Effects on Safety, Tolerability, and Biomarkers in Alzheimer's Disease. Ann Neurol, 88:183-194.

[19] Tremblay MA, Acker CM, Davies P (2010). Tau phosphorylated at tyrosine 394 is found in Alzheimer's disease tangles and can be a product of the Abl-related kinase, Arg. J Alzheimers Dis, 19:721-733.

[20] Schlatterer SD, Acker CM, Davies P (2011). c-Abl in neurodegenerative disease. J Mol Neurosci, 45:445452.

[21] Imam SZ, Zhou Q, Yamamoto A, Valente AJ, Ali SF, Bains M, et al. (2011). Novel regulation of parkin function through c-Abl-mediated tyrosine phosphorylation: implications for Parkinson's disease. J Neurosci, 31:157-163.

[22] Ko HS, Lee Y, Shin JH, Karuppagounder SS, Gadad BS, Koleske AJ, et al. (2010). Phosphorylation by the c-Abl protein tyrosine kinase inhibits parkin's ubiquitination and protective function. Proc Natl Acad Sci U S A, 107:16691-16696.

[23] Schlatterer SD, Tremblay MA, Acker CM, Davies P (2011). Neuronal c-Abl overexpression leads to neuronal loss and neuroinflammation in the mouse forebrain. J Alzheimers Dis, 25:119-133.

[24] Lawana V, Singh N, Sarkar S, Charli A, Jin H, Anantharam V, et al. (2017). Involvement of c-Abl Kinase in Microglial Activation of NLRP3 Inflammasome and Impairment in Autolysosomal System. J Neuroimmune Pharmacol, 12:624-660.

[25] Lee SJ, Seo BR, Choi EJ, Koh JY (2014). The role of reciprocal activation of $\mathrm{cAbl}$ and Mst 1 in the oxidative death of cultured astrocytes. Glia, 62:639-648.

[26] Song GJ, Rahman MH, Jha MK, Gupta DP, Park SH, Kim JH, et al. (2019). A Bcr-Abl Inhibitor GNF-2 Attenuates Inflammatory Activation of Glia and Chronic Pain. Front Pharmacol, 10:543.

[27] Cunningham C, Wilcockson DC, Campion S, Lunnon K, Perry VH (2005). Central and systemic endotoxin challenges exacerbate the local inflammatory response and increase neuronal death during chronic neurodegeneration. J Neurosci, 25:9275-9284.

[28] Fakhoury M (2018). Microglia and Astrocytes in Alzheimer's Disease: Implications for Therapy. Curr Neuropharmacol, 16:508-518.

[29] Holmes C, El-Okl M, Williams AL, Cunningham C, Wilcockson D, Perry VH (2003). Systemic infection, interleukin 1beta, and cognitive decline in Alzheimer's disease. J Neurol Neurosurg Psychiatry, 74:788-789.

[30] Meraz-Rios MA, Toral-Rios D, Franco-Bocanegra D, Villeda-Hernandez J, Campos-Pena V (2013). Inflammatory process in Alzheimer's Disease. Front Integr Neurosci, 7:59.

[31] Iglesias J, Morales L, Barreto GE (2017). Metabolic and Inflammatory Adaptation of Reactive Astrocytes: Role of PPARs. Mol Neurobiol, 54:2518-2538.

[32] Ksiezakowska-Lakoma K, Zyla M, Wilczynski JR (2014). Mitochondrial dysfunction in cancer. Prz Menopauzalny, 13:136-144.

[33] Hsu CC, Tseng LM, Lee HC (2016). Role of mitochondrial dysfunction in cancer progression. Exp Biol Med (Maywood), 241:1281-1295.

[34] Albensi BC (2019). Dysfunction of mitochondria: Implications for Alzheimer's disease. Int Rev Neurobiol, 145:13-27.

[35] Obulesu M, Jhansilakshmi M (2014). Neuroinflammation in Alzheimer's disease: an understanding of physiology and pathology. Int $\mathrm{J}$ Neurosci, 124:227-235.

[36] Obulesu M, Lakshmi MJ (2014). Apoptosis in Alzheimer's disease: an understanding of the physiology, pathology and therapeutic avenues. Neurochem Res, 39:2301-2312.

[37] Silva DF, Selfridge JE, Lu J, E L, Roy N, Hutfles L, et al. (2013). Bioenergetic flux, mitochondrial mass and mitochondrial morphology dynamics in $\mathrm{AD}$ and $\mathrm{MCI}$ cybrid cell lines. Hum Mol Genet, 22:3931-3946.

[38] Scatena R (2012). Mitochondria and cancer: a growing role in apoptosis, cancer cell metabolism and dedifferentiation. Adv Exp Med Biol, 942:287-308.

[39] Porporato PE, Filigheddu N, Pedro JMB, Kroemer G, Galluzzi L (2018). Mitochondrial metabolism and cancer. Cell Res, 28:265-280.

[40] Hauptmann S, Scherping I, Drose S, Brandt U, Schulz KL, Jendrach M, et al. (2009). Mitochondrial dysfunction: an early event in Alzheimer pathology accumulates with age in $\mathrm{AD}$ transgenic mice. Neurobiol Aging, 30:1574-1586.

[41] Merlo E, Freudenthal R, Maldonado H, Romano A (2005). Activation of the transcription factor NFkappaB by retrieval is required for long-term memory reconsolidation. Learn Mem, 12:23-29.

[42] Manczak M, Anekonda TS, Henson E, Park BS, Quinn J, Reddy PH (2006). Mitochondria are a direct site of A beta accumulation in Alzheimer's disease neurons: implications for free radical generation and oxidative damage in disease progression. Hum Mol Genet, 15:1437-1449.

[43] Tilstra JS, Clauson CL, Niedernhofer LJ, Robbins PD (2011). NF-kappaB in Aging and Disease. Aging Dis, 2:449-465. 
[44] Adlimoghaddam A, Sabbir MG, Albensi BC (2016). Ammonia as a Potential Neurotoxic Factor in Alzheimer's Disease. Front Mol Neurosci, 9:57.

[45] Amsalem Z, Arif T, Shteinfer-Kuzmine A, ChalifaCaspi V, Shoshan-Barmatz V (2020). The Mitochondrial Protein VDAC1 at the Crossroads of Cancer Cell Metabolism: The Epigenetic Link. Cancers (Basel), 12.

[46] Chua LM, Lim ML, Wong BS (2013). The Kunitzprotease inhibitor domain in amyloid precursor protein reduces cellular mitochondrial enzymes expression and function. Biochem Biophys Res Commun, 437:642-647.

[47] Reddy PH, Manczak M, Yin X (2017). MitochondriaDivision Inhibitor 1 Protects Against Amyloid-beta induced Mitochondrial Fragmentation and Synaptic Damage in Alzheimer's Disease. J Alzheimers Dis, 58:147-162.

[48] Wang X, Su B, Fujioka H, Zhu X (2008). Dynaminlike protein 1 reduction underlies mitochondrial morphology and distribution abnormalities in fibroblasts from sporadic Alzheimer's disease patients. Am J Pathol, 173:470-482.

[49] Wang X, Su B, Lee HG, Li X, Perry G, Smith MA, et al. (2009). Impaired balance of mitochondrial fission and fusion in Alzheimer's disease. J Neurosci, 29:9090-9103.

[50] Oliver D, Reddy PH (2019). Dynamics of DynaminRelated Protein 1 in Alzheimer's Disease and Other Neurodegenerative Diseases. Cells, 8.

[51] DiDonato JA, Mercurio F, Karin M (2012). NFkappaB and the link between inflammation and cancer. Immunol Rev, 246:379-400.

[52] Karin M (2009). NF-kappaB as a critical link between inflammation and cancer. Cold Spring Harb Perspect Biol, 1:a000141.

[53] Mauro C, Leow SC, Anso E, Rocha S, Thotakura AK, Tornatore L, et al. (2011). NF-kappaB controls energy homeostasis and metabolic adaptation by upregulating mitochondrial respiration. Nat Cell Biol, 13:12721279.

[54] Shi C, Zhu X, Wang J, Long D (2014). Intromitochondrial IkappaB/NF-kappaB signaling pathway is involved in amyloid beta peptide-induced mitochondrial dysfunction. J Bioenerg Biomembr, 46:371-376.

[55] Laforge M, Rodrigues V, Silvestre R, Gautier C, Weil $\mathrm{R}$, Corti O, et al. (2016). NF-kappaB pathway controls mitochondrial dynamics. Cell Death Differ, 23:89-98.

[56] Cogswell PC, Kashatus DF, Keifer JA, Guttridge DC, Reuther JY, Bristow C, et al. (2003). NF-kappa B and I kappa B alpha are found in the mitochondria. Evidence for regulation of mitochondrial gene expression by NF-kappa B. J Biol Chem, 278:29632968.

[57] Albensi BC (2019). What Is Nuclear Factor Kappa B (NF-kappaB) Doing in and to the Mitochondrion? Front Cell Dev Biol, 7:154.

[58] Moretti M, Bennett J, Tornatore L, Thotakura AK, Franzoso G (2012). Cancer: NF-kappaB regulates
2243

Lamas O, Moreno-Aliaga MJ, Martinez JA, Marti A (2003). NF-kappa B-binding activity in an animal dietinduced overweightness model and the impact of subsequent energy restriction. Biochem Biophys Res Commun, 311:533-539.

[60] Zhong Z, Umemura A, Sanchez-Lopez E, Liang S, Shalapour S, Wong J, et al. (2016). NF-kappaB Restricts Inflammasome Activation via Elimination of Damaged Mitochondria. Cell, 164:896-910.

[61] Canto C, Auwerx J (2010). AMP-activated protein kinase and its downstream transcriptional pathways. Cell Mol Life Sci, 67:3407-3423.

[62] $\mathrm{Wu} \mathrm{H}$, Kanatous SB, Thurmond FA, Gallardo T, Isotani E, Bassel-Duby R, et al. (2002). Regulation of mitochondrial biogenesis in skeletal muscle by CaMK. Science, 296:349-352.

[63] Lin J, Handschin C, Spiegelman BM (2005). Metabolic control through the PGC-1 family of transcription coactivators. Cell Metab, 1:361-370.

[64] Gureev AP, Shaforostova EA, Popov VN (2019). Regulation of Mitochondrial Biogenesis as a Way for Active Longevity: Interaction Between the Nrf2 and PGC-1alpha Signaling Pathways. Front Genet, 10:435.

[65] Ventura-Clapier R, Garnier A, Veksler V (2008). Transcriptional control of mitochondrial biogenesis: the central role of PGC-1alpha. Cardiovasc Res, 79:208-217.

[66] Schildge S, Bohrer C, Beck K, Schachtrup C (2013). Isolation and culture of mouse cortical astrocytes. J Vis Exp.

[67] Marcus DL, Strafaci JA, Freedman ML (2006). Differential neuronal expression of manganese superoxide dismutase in Alzheimer's disease. Med Sci Monit, 12:BR8-14.

[68] Acevedo G, Padala NK, Ni L, Jonakait GM (2013). Astrocytes inhibit microglial surface expression of dendritic cell-related co-stimulatory molecules through a contact-mediated process. J Neurochem, 125:575-587.

[69] Guttenplan KA, Liddelow SA (2019). Astrocytes and microglia: Models and tools. J Exp Med, 216:71-83.

[70] Lee J, Rhee MH, Kim E, Cho JY (2012). BAY 11-7082 is a broad-spectrum inhibitor with anti-inflammatory activity against multiple targets. Mediators Inflamm, 2012:416036.

[71] Wan F, Lenardo MJ (2010). The nuclear signaling of NF-kappaB: current knowledge, new insights, and future perspectives. Cell Res, 20:24-33.

[72] Silveira E, Cavalcante IP, Kremer JL, de Mendonca POR, Lotfi CFP (2018). The tyrosine kinase inhibitor nilotinib is more efficient than mitotane in decreasing cell viability in spheroids prepared from adrenocortical carcinoma cells. Cancer Cell Int, 18:29. Weigel MT, Rath K, Alkatout I, Wenners AS, Schem C, Maass N, et al. (2014). Nilotinib in combination with carboplatin and paclitaxel is a candidate for ovarian cancer treatment. Oncology, 87:232-245. Chen TC, Yu MC, Chien CC, Wu MS, Lee YC, Chen 
YC (2016). Nilotinib reduced the viability of human ovarian cancer cells via mitochondria-dependent apoptosis, independent of JNK activation. Toxicol In Vitro, 31:1-11.

[75] Weisberg E, Manley PW, Breitenstein W, Bruggen J, Cowan-Jacob SW, Ray A, et al. (2005). Characterization of AMN107, a selective inhibitor of native and mutant Bcr-Abl. Cancer Cell, 7:129-141.

[76] Bubber P, Haroutunian V, Fisch G, Blass JP, Gibson GE (2005). Mitochondrial abnormalities in Alzheimer brain: mechanistic implications. Ann Neurol, 57:695703.

[77] Cabezas-Opazo FA, Vergara-Pulgar K, Perez MJ, Jara C, Osorio-Fuentealba C, Quintanilla RA (2015). Mitochondrial Dysfunction Contributes to the Pathogenesis of Alzheimer's Disease. Oxid Med Cell Longev, 2015:509654.

[78] Fecher C, Trovo L, Muller SA, Snaidero N, Wettmarshausen J, Heink S, et al. (2019). Cell-typespecific profiling of brain mitochondria reveals functional and molecular diversity. Nat Neurosci, 22:1731-1742.

[79] Ioannou MS, Jackson J, Sheu SH, Chang CL, Weigel AV, Liu H, et al. (2019). Neuron-Astrocyte Metabolic Coupling Protects against Activity-Induced Fatty Acid Toxicity. Cell, 177:1522-1535 e1514.

[80] Fernandez-Fernandez S, Almeida A, Bolanos JP (2012). Antioxidant and bioenergetic coupling between neurons and astrocytes. Biochem J, 443:3-11.

[81] Rose J, Brian C, Woods J, Pappa A, Panayiotidis MI, Powers R, et al. (2017). Mitochondrial dysfunction in glial cells: Implications for neuronal homeostasis and survival. Toxicology, 391:109-115.

[82] Park J, Choi H, Min JS, Park SJ, Kim JH, Park HJ, et al. (2013). Mitochondrial dynamics modulate the expression of pro-inflammatory mediators in microglial cells. J Neurochem, 127:221-232.

[83] Orihuela R, McPherson CA, Harry GJ (2016). Microglial M1/M2 polarization and metabolic states. Br J Pharmacol, 173:649-665.

[84] Jiang T, Cadenas E (2014). Astrocytic metabolic and inflammatory changes as a function of age. Aging Cell, 13:1059-1067.

[85] Campuzano O, Castillo-Ruiz MM, Acarin L, Castellano B, Gonzalez B (2009). Increased levels of proinflammatory cytokines in the aged rat brain attenuate injury-induced cytokine response after excitotoxic damage. J Neurosci Res, 87:2484-2497.

[86] Zhang G, Li J, Purkayastha S, Tang Y, Zhang H, Yin $\mathrm{Y}$, et al. (2013). Hypothalamic programming of systemic ageing involving IKK-beta, NF-kappaB and GnRH. Nature, 497:211-216.

[87] Ojeda DS, Grasso D, Urquiza J, Till A, Vaccaro MI, Quarleri J (2018). Cell Death Is Counteracted by Mitophagy in HIV-Productively Infected Astrocytes but Is Promoted by Inflammasome Activation Among Non-productively Infected Cells. Front Immunol, 9:2633.

[88] Lonskaya I, Hebron ML, Desforges NM, Schachter JB, Moussa CE (2014). Nilotinib-induced autophagic changes increase endogenous parkin level and ubiquitination, leading to amyloid clearance. J Mol Med (Berl), 92:373-386.

[89] Telford JE, Kilbride SM, Davey GP (2009). Complex $\mathrm{I}$ is rate-limiting for oxygen consumption in the nerve terminal. J Biol Chem, 284:9109-9114.

[90] Davey GP, Peuchen S, Clark JB (1998). Energy thresholds in brain mitochondria. Potential involvement in neurodegeneration. J Biol Chem, 273:12753-12757.

[91] Djordjevic J, Roy Chowdhury S, Snow WM, Perez C, Cadonic C, Fernyhough P, et al. (2020). Early Onset of Sex-Dependent Mitochondrial Deficits in the Cortex of 3xTg Alzheimer's Mice. Cells, 9.

[92] Snow WM, Cadonic C, Cortes-Perez C, Roy Chowdhury SK, Djordjevic J, Thomson E, et al. (2018). Chronic dietary creatine enhances hippocampal-dependent spatial memory, bioenergetics, and levels of plasticity-related proteins associated with NF-kappaB. Learn Mem, 25:54-66.

[93] Soto IC, Fontanesi F, Liu J, Barrientos A (2012). Biogenesis and assembly of eukaryotic cytochrome c oxidase catalytic core. Biochim Biophys Acta, 1817:883-897.

[94] Bazil JN, Buzzard GT, Rundell AE (2010). Modeling mitochondrial bioenergetics with integrated volume dynamics. PLoS Comput Biol, 6:e1000632.

[95] Leipnitz G, Mohsen AW, Karunanidhi A, Seminotti B, Roginskaya VY, Markantone DM, et al. (2018). Evaluation of mitochondrial bioenergetics, dynamics, endoplasmic reticulum-mitochondria crosstalk, and reactive oxygen species in fibroblasts from patients with complex I deficiency. Sci Rep, 8:1165.

[96] Rossignol O, Dodson JJ, Guderley H (2011). Relationship between metabolism, sex and reproductive tactics in young Atlantic salmon (Salmo salar L.). Comp Biochem Physiol A Mol Integr Physiol, 159:82-91.

[97] Parone PA, Da Cruz S, Tondera D, Mattenberger Y, James DI, Maechler P, et al. (2008). Preventing mitochondrial fission impairs mitochondrial function and leads to loss of mitochondrial DNA. PLoS One, 3:e3257.

[98] Westermann B (2012). Bioenergetic role of mitochondrial fusion and fission. Biochim Biophys Acta, 1817:1833-1838.

[99] Figge MT, Reichert AS, Meyer-Hermann M, Osiewacz HD (2012). Deceleration of fusion-fission cycles improves mitochondrial quality control during aging. PLoS Comput Biol, 8:e1002576.

[100] Sheng B, Wang X, Su B, Lee HG, Casadesus G, Perry $\mathrm{G}$, et al. (2012). Impaired mitochondrial biogenesis contributes to mitochondrial dysfunction in Alzheimer's disease. J Neurochem, 120:419-429.

[101] Trimmer PA, Borland MK (2005). Differentiated Alzheimer's disease transmitochondrial cybrid cell lines exhibit reduced organelle movement. Antioxid Redox Signal, 7:1101-1109.

[102] Wang X, Su B, Zheng L, Perry G, Smith MA, Zhu X (2009). The role of abnormal mitochondrial dynamics 
in the pathogenesis of Alzheimer's disease. J Neurochem, 109 Suppl 1:153-159.

[103] Manczak M, Calkins MJ, Reddy PH (2011). Impaired mitochondrial dynamics and abnormal interaction of amyloid beta with mitochondrial protein Drp1 in neurons from patients with Alzheimer's disease: implications for neuronal damage. Hum Mol Genet, 20:2495-2509.

[104] Joshi AU, Ebert AE, Haileselassie B, Mochly-Rosen D (2019). Drp1/Fis1-mediated mitochondrial fragmentation leads to lysosomal dysfunction in cardiac models of Huntington's disease. J Mol Cell Cardiol, 127:125-133.

[105] Chen H, Chomyn A, Chan DC (2005). Disruption of fusion results in mitochondrial heterogeneity and dysfunction. J Biol Chem, 280:26185-26192.

[106] Reddy PH (2014). Inhibitors of mitochondrial fission as a therapeutic strategy for diseases with oxidative stress and mitochondrial dysfunction. J Alzheimers Dis, 40:245-256.

[107] Rappold PM, Cui M, Grima JC, Fan RZ, de MesyBentley KL, Chen L, et al. (2014). Drp1 inhibition attenuates neurotoxicity and dopamine release deficits in vivo. Nat Commun, 5:5244.

[108] Pich S, Bach D, Briones P, Liesa M, Camps M, Testar $\mathrm{X}$, et al. (2005). The Charcot-Marie-Tooth type 2A gene product, Mfn2, up-regulates fuel oxidation through expression of OXPHOS system. Hum Mol Genet, 14:1405-1415.

[109] Srinivasan S, Guha M, Kashina A, Avadhani NG (2017). Mitochondrial dysfunction and mitochondrial dynamics-The cancer connection. Biochim Biophys Acta Bioenerg, 1858:602-614.

[110] Chen H, Vermulst M, Wang YE, Chomyn A, Prolla TA, McCaffery JM, et al. (2010). Mitochondrial fusion is required for mtDNA stability in skeletal muscle and tolerance of mtDNA mutations. Cell, 141:280-289.

[111] Szabo A, Sumegi K, Fekete K, Hocsak E, Debreceni B, Setalo G, Jr., et al. (2018). Activation of mitochondrial fusion provides a new treatment for mitochondria-related diseases. Biochem Pharmacol, 150:86-96.

[112] Yoneda M, Miyatake T, Attardi G (1994). Complementation of mutant and wild-type human mitochondrial DNAs coexisting since the mutation event and lack of complementation of DNAs introduced separately into a cell within distinct organelles. Mol Cell Biol, 14:2699-2712.

[113] Schon EA, Gilkerson RW (2010). Functional complementation of mitochondrial DNAs: mobilizing mitochondrial genetics against dysfunction. Biochim Biophys Acta, 1800:245-249.

[114] Yang L, Long Q, Liu J, Tang H, Li Y, Bao F, et al. (2015). Mitochondrial fusion provides an 'initial metabolic complementation' controlled by mtDNA. Cell Mol Life Sci, 72:2585-2598.

[115] Twig G, Shirihai OS (2011). The interplay between mitochondrial dynamics and mitophagy. Antioxid Redox Signal, 14:1939-1951.

[116] van Horssen J, van Schaik P, Witte M (2019).
Inflammation and mitochondrial dysfunction: A vicious circle in neurodegenerative disorders? Neurosci Lett, 710:132931.

[117] Gupta AS, Waters MR, Biswas DD, Brown LN, Surace MJ, Floros C, et al. (2019). RelB controls adaptive responses of astrocytes during sterile inflammation. Glia, 67:1449-1461.

[118] Simmons LJ, Surles-Zeigler MC, Li Y, Ford GD, Newman GD, Ford BD (2016). Regulation of inflammatory responses by neuregulin-1 in brain ischemia and microglial cells in vitro involves the NFkappa B pathway. J Neuroinflammation, 13:237.

[119] Kiebala M, Polesskaya O, Yao Z, Perry SW, Maggirwar SB (2010). Nuclear factor-kappa B family member RelB inhibits human immunodeficiency virus-1 Tat-induced tumor necrosis factor-alpha production. PLoS One, 5:e11875.

[120] Kaltschmidt B, Kaltschmidt C (2009). NF-kappaB in the nervous system. Cold Spring Harb Perspect Biol, 1:a001271.

[121] Mattson MP, Meffert MK (2006). Roles for NFkappaB in nerve cell survival, plasticity, and disease. Cell Death Differ, 13:852-860.

[122] Hsiao HY, Chen YC, Chen HM, Tu PH, Chern Y (2013). A critical role of astrocyte-mediated nuclear factor-kappaB-dependent inflammation in Huntington's disease. Hum Mol Genet, 22:1826-1842.

[123] Carrero I, Gonzalo MR, Martin B, Sanz-Anquela JM, Arevalo-Serrano J, Gonzalo-Ruiz A (2012). Oligomers of beta-amyloid protein (Abeta1-42) induce the activation of cyclooxygenase- 2 in astrocytes via an interaction with interleukin-1beta, tumour necrosis factor-alpha, and a nuclear factor kappa-B mechanism in the rat brain. Exp Neurol, 236:215-227.

[124] Lian H, Yang L, Cole A, Sun L, Chiang AC, Fowler SW, et al. (2015). NFkappaB-activated astroglial release of complement $\mathrm{C} 3$ compromises neuronal morphology and function associated with Alzheimer's disease. Neuron, 85:101-115.

[125] Migheli A, Piva R, Atzori C, Troost D, Schiffer D (1997). c-Jun, JNK/SAPK kinases and transcription factor NF-kappa B are selectively activated in astrocytes, but not motor neurons, in amyotrophic lateral sclerosis. J Neuropathol Exp Neurol, 56:13141322 .

[126] Gilmore TD (2006). Introduction to NF-kappaB: players, pathways, perspectives. Oncogene, 25:66806684.

[127] Aisen PS, Davis KL (1994). Inflammatory mechanisms in Alzheimer's disease: implications for therapy. Am J Psychiatry, 151:1105-1113.

[128] Block ML, Zecca L, Hong JS (2007). Microgliamediated neurotoxicity: uncovering the molecular mechanisms. Nat Rev Neurosci, 8:57-69.

[129] Liddelow SA, Guttenplan KA, Clarke LE, Bennett FC, Bohlen CJ, Schirmer L, et al. (2017). Neurotoxic reactive astrocytes are induced by activated microglia. Nature, 541:481-487.

[130] Albensi BC, Mattson MP (2000). Evidence for the 
involvement of TNF and NF-kappaB in hippocampal synaptic plasticity. Synapse, 35:151-159.

[131] Engelmann C, Haenold R (2016). Transcriptional Control of Synaptic Plasticity by Transcription Factor NF-kappaB. Neural Plast, 2016:7027949.

[132] Salles A, Romano A, Freudenthal R (2014). Synaptic NF-kappa B pathway in neuronal plasticity and memory. J Physiol Paris, 108:256-262.

[133] Meffert MK, Chang JM, Wiltgen BJ, Fanselow MS, Baltimore D (2003). NF-kappa B functions in synaptic signaling and behavior. Nat Neurosci, 6:1072-1078.

[134] Dresselhaus EC, Meffert MK (2019). Cellular Specificity of NF-kappaB Function in the Nervous System. Front Immunol, 10:1043.

[135] Chin ER (2004). The role of calcium and calcium/calmodulin-dependent kinases in skeletal muscle plasticity and mitochondrial biogenesis. Proc Nutr Soc, 63:279-286.

[136] Ishiguro K, Green T, Rapley J, Wachtel H, Giallourakis C, Landry A, et al. (2006). $\mathrm{Ca} 2+$ calmodulin-dependent protein kinase II is a modulator of CARMA1-mediated NF-kappaB activation. Mol Cell Biol, 26:5497-5508.
[137]

Sweeney G, Song J (2016). The association between PGC-1alpha and Alzheimer's disease. Anat Cell Biol, 49:1-6.

[138] Jornayvaz FR, Shulman GI (2010). Regulation of mitochondrial biogenesis. Essays Biochem, 47:69-84.

[139] Wu Z, Puigserver P, Andersson U, Zhang C, Adelmant $\mathrm{G}$, Mootha V, et al. (1999). Mechanisms controlling mitochondrial biogenesis and respiration through the thermogenic coactivator PGC-1. Cell, 98:115-124.

[140] Feige JN, Auwerx J (2007). Transcriptional coregulators in the control of energy homeostasis. Trends Cell Biol, 17:292-301.

[141] Rodgers JT, Lerin C, Gerhart-Hines Z, Puigserver P (2008). Metabolic adaptations through the PGC-1 alpha and SIRT1 pathways. FEBS Lett, 582:46-53.

[142] Jager S, Handschin C, St-Pierre J, Spiegelman BM (2007). AMP-activated protein kinase (AMPK) action in skeletal muscle via direct phosphorylation of PGC1alpha. Proc Natl Acad Sci U S A, 104:12017-12022.

[143] Tufekci KU, Civi Bayin E, Genc S, Genc K (2011). The Nrf2/ARE Pathway: A Promising Target to Counteract Mitochondrial Dysfunction in Parkinson's Disease. Parkinsons Dis, 2011:314082. 